\title{
Crack Evolution Characteristics and Cracking Mechanism of Red Beds in Central Sichuan during Seepage and Swelling
}

\author{
Zhe Zhou, ${ }^{1,2}$ Shanxiong Chen, ${ }^{1}$ Yinhui Wang, ${ }^{1,2}$ and Zhangjun Dai ${ }^{1}$ \\ ${ }^{1}$ State Key Laboratory of Geomechanics and Geotechnical Engineering, Institute of Rock and Soil Mechanics, Chinese Academy \\ of Sciences, Wuhan 430071, China \\ ${ }^{2}$ School of Earth Sciences, University of Chinese Academy of Sciences, Beijing 100049, China
}

Correspondence should be addressed to Zhangjun Dai; zjdai@whrsm.ac.cn

Received 25 March 2021; Revised 2 April 2021; Accepted 9 April 2021; Published 28 April 2021

Academic Editor: Yu Wang

Copyright (c) 2021 Zhe Zhou et al. This is an open access article distributed under the Creative Commons Attribution License, which permits unrestricted use, distribution, and reproduction in any medium, provided the original work is properly cited.

Crack is one of the important factors affecting the engineering characteristics of expansive rock and soil. In order to study the evolution characteristics and cracking mechanism of red beds in Central Sichuan during seepage and swelling, multiple groups of cracking tests are conducted under different initial states with a self-made device. In addition, combining swelling-softening mechanism of expansive rock and numerical analysis, the swelling-cracking mechanism is studied. The following research results are obtained. (1) The evolution process of swelling cracks is divided into three stages: the generation stage, the rapid development stage, and the stabilization stage. In the rapid development stage, the increase in the crack degree accounts for $90 \%$ of the whole process. (2) The final crack degree of the sample is related to the initial water content, water absorption method, and clay mineral content. The lower the initial water content, the greater the final crack degree of the sample. The final crack degree under the soaking water absorption method is greater than that under the capillary water absorption method, and the final crack degree of mudstone is greater than that of argillaceous sandstone and sandstone. (3) The development of swelling cracks is controlled by three significant values of water absorption, which are $w_{1}, w_{2}$, and $w_{3}$, respectively, representing the beginning of cracking, the starting of the rapid development stage, and the starting of the stabilization stage. Among them, $w_{2}$ is of great significance in engineering practice. It shows that the development of cracks has entered a stage of rapid development, and the crack degree in this stage will increase exponentially with water absorption. (4) Uneven water absorption and uneven distribution of clay minerals lead to uneven swelling of expansive rock, which in turn generates swelling stress. Under the combined action of swelling stress and water swelling-softening, the internal structure of the rock is destroyed, leading to the generation and development of the cracks. Due to the different causes of uneven expansion, the mechanical mechanism of cracking and the shape of the resulting cracks will be different.

\section{Introduction}

Crack is one of the important factors affecting the engineering properties of rock and soil. Previous studies have shown that cracks generate and expand under external stress, freeze-thaw, and dry-wet cycles, causing structural damage and strength attenuation of rock and soil, and changing the seepage characteristics of rock and soil [1-6]. Especially in expansive rock and soil engineering, fissures will cause serious deterioration of the engineering properties of the rock and soil mass, which will cause serious geological disasters and damage to engineering buildings and structures $[7,8]$.
Therefore, relevant geotechnical practitioners have conducted a large number of systematic studies on the expansive rock or soil cracks. These researches involve crack development characteristics and quantitative index analysis, influence factors of the development and expansion of cracks, and cracking mechanisms.

At present, there are a lot of research results on the crack development characteristics and quantitative description of expansive rock/soil. Chen [9] and Lu et al. [10] conducted CT test research on the crack evolution of expansive soil cracks. The research results show the process of crack development, new cracks connecting, and the formation of a crack 


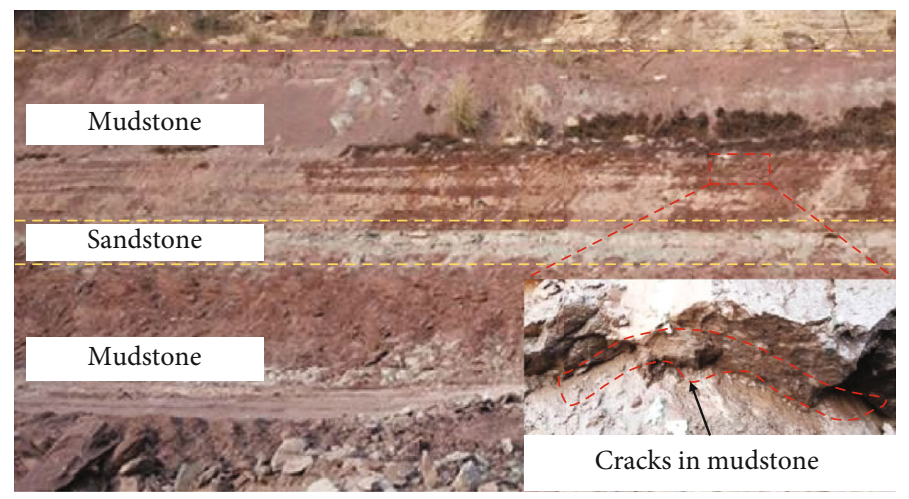

FIgURE 1: The red bed in Central Sichuan.

network. Yi et al. [11] studied the fractal characteristics of the fractured structure of expansive soils based on the fractal theory. Wang et al. [12] based on the numerical processing technology of image grayscale and binarization proposed the concept and quantitative description method of fissures in expansive rock. Li et al. [13] optimized and improved the image processing method of shrinkage cracks in expansive soil and the method of extracting crack features. Wei et al. [14] conducted a quantitative analysis of the cracks on the surface of expansive soil samples through indoor dry-wet cycle tests, and studied the variation of the geometric structure and morphological characteristics of the crack network with the number of cycles.

The evolution of cracks is greatly affected by the external environment. Tang et al. [15] studied the effect of temperature on the shrinkage cracks of expansive soil and found that the shrinkage cracks have obvious temperature effects. Mao et al. [16] studied the effects of different initial damage degrees, different numbers of dry-wet cycles, and coupled conditions of the two on the development and evolution of pores and fissures in expansive soils, as well as the corresponding soil deformation and mechanical behavior. $\mathrm{Hu}$ et al. [17] conducted a CT scan test on the undisturbed expansive soil through the dry-wet cycle, and studied the relationship between the three-dimensional space cracks and the dry-wet cycle from both qualitative and quantitative aspects. Lou et al. [18, 19] studied the influence of size and temperature on the evolution of cracks in expansive soils, and combined with the tensile failure theory of soil cracking and the shrinkage and evaporation of the sample, the cracking mechanism of soil under the influence of thickness is theoretically analyzed.

On the generation and propagation mechanism of cracks, many researchers have conducted considerable in-depth researches from the aspects of experiment, theory, and numerical model. Konrad and Ayad [20] established a theoretical model of clay cracking under the condition of surface evaporation through the field test results of clay dry cracking; Yao et al. [21] used elastic theory and fracture mechanics principle to put forward the mathematical expression of crack propagation depth, which basically determined the approximate depth of crack development. Ma et al. [22] studied the process of crack generation, propagation, and expansion under the condition of dehumidification, and summarized the laws of crack generation, propagation, and expansion. Wu et al. [23] studied the development mechanism of initial cracks in expansive soil when water content changes, and established a theoretical model. Yin et al. [8] proposed that high shrinkage and low permeability are the basic reasons for the multicracks of expansive soils, and further discussed the generation mechanism and development process of cracks in expansive soils.

The above studies are mainly aimed at the shrinkage cracks of the expansive rock/soil under the condition of water loss. However, under the condition of water absorption, the expansive soil generally does not develop cracks, but the expansive rock will develop and expand cracks. Many scholars have observed the development and expansion of cracks in the expansion test and disintegration test of expansive rock [24-26]. In response to this phenomenon, the researchers only carried out some qualitative descriptions and analyses, and believed that the evolution of fissures was one of the reasons for the volume expansion and the disintegration of expansive rock. However, these studies did not quantitatively analyze the evolution characteristics of swelling cracks nor did they in-depth study of the mechanism of swelling cracks.

This work takes the red-bed mudstone in Central Sichuan as the research object. Through the self-made soft rock water absorption and cracking test device, multiple sets of unconfined swelling-cracking tests under different initial conditions were carried out. The crack field information is visualized through image recognition and interpretation technology. Combined with the analysis of fissure quantitative indicators, the evolution law and influencing factors of swelling cracks in red-bed mudstone are studied, and the relationship curve between the crack degree and water absorption is established. Finally, combining the swelling mechanism and numerical analysis, cracking mechanism of expansive rock under water swelling condition is studied.

\section{Experimental Material and Methodology}

2.1. Rock Material and Its Basic Physical Properties. The expansive rock materials studied in this work were acquired from red beds in Central Sichuan (Figure 1). The red bed is 
TABLE 1: X-ray diffraction results (unit: \%).

\begin{tabular}{lccccccccc}
\hline Lithology & Montmorillonite & Illite & Chlorite & Kaolinite & Calcite & Hematite & Quartz & Albite & Plagioclase \\
\hline Mudstone & 20 & 15 & & 5 & & 1 & 38 & 21 & \\
Argillaceous sandstone & 5 & 13 & 5 & & 2 & 3 & 37 & 27 & 8 \\
Sandstone & & 11 & 4 & 12 & 3 & & 31 & 27 & 12 \\
\hline
\end{tabular}
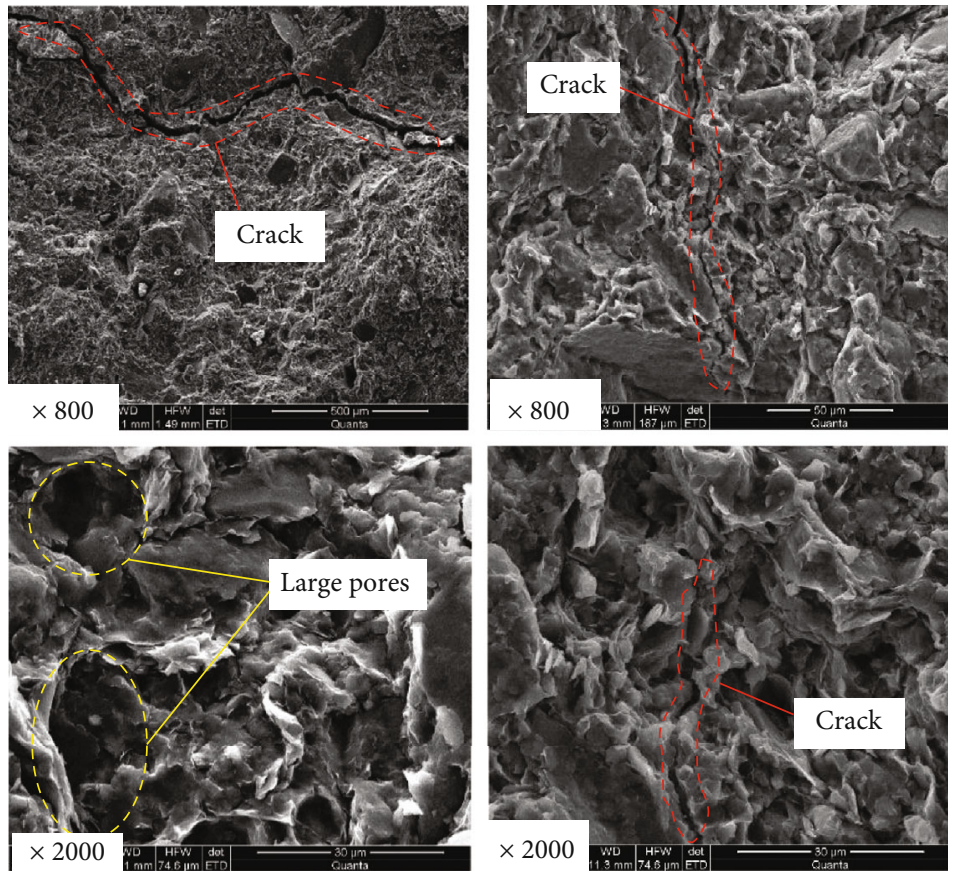

FiguRE 2: SEM results of mudstone.

the Middle Jurassic Upper Shaximiao Formation $\left(\mathrm{J}_{2} \mathrm{~s}\right)$ mudstone intercalated with sandstone. The mudstone is purplered, argillaceous cemented, with well-developed fissures, contains more hydrophilic minerals, and is easy to disintegrate. Laboratory swelling test research shows that the average swelling force of the original rock is $700 \mathrm{kPa}$, and the average free expansion rate of rock powder is $27.9 \%$, which has a large expansibility $[27,28]$. The sandstone is gray-green/gray-white, mostly feldspar quartz sandstone, with medium-fine grain structure, argillaceous cement, hard texture, and nonswelling.

Table 1 shows the X-ray diffraction results of the test samples. From the results, mudstone contains $20 \%$ montmorillonite and $15 \%$ illite, argillaceous sandstone contains just $5 \%$ montmorillonite and $13 \%$ illite, and sandstone contains only $11 \%$ illite. According to SEM imaging analysis of mudstone sample in Figure 2, microcracks are developed, and clay minerals are stacked in flakes with no obvious orientation arrangement. In addition, there are some large pores and many small pores that can be observed.

2.2. Test Method. In the process of water swelling of mudstone, cracks must generate and develop in threedimensional space. However, due to limited conditions, the sample cannot be scanned by three-dimensional CT (com-

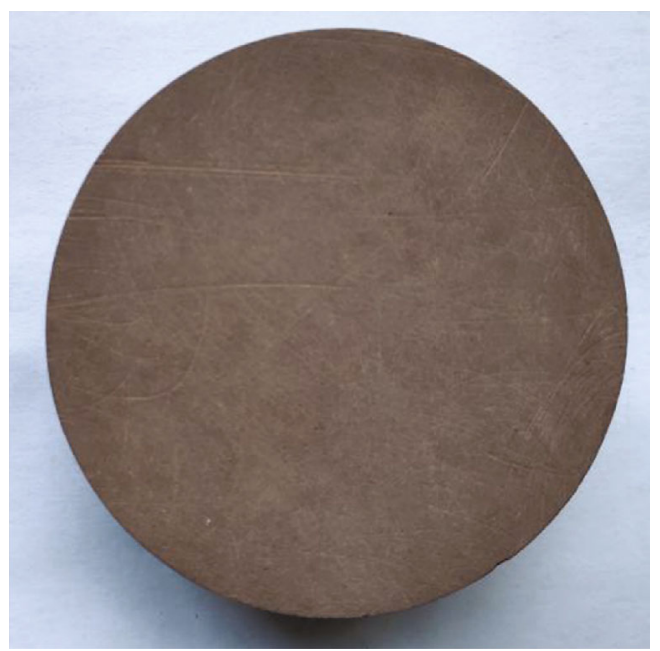

FIGURE 3: Rock sample.

puted tomography) during the test. Therefore, the test mainly focuses on the observation and quantitative analysis of surface cracks on the sample. The sample is a rock cake obtained by cutting the core (Figure 3), and its size is $\phi \times h=64.0 \mathrm{~mm} \times 24.0 \mathrm{~mm}$. The selection of the thickness 
TABLE 2: Basic physical properties of samples.

\begin{tabular}{|c|c|c|c|c|c|c|}
\hline Sample number & Lithology & Method of water absorption & $\begin{array}{c}\text { Initial water content } \\
(\%)\end{array}$ & $\begin{array}{l}\text { Thickness } \\
(\mathrm{mm})\end{array}$ & $\begin{array}{l}\text { Diameter } \\
(\mathrm{mm})\end{array}$ & $\begin{array}{l}\text { Natural density } \\
\left(\mathrm{g} / \mathrm{cm}^{3}\right)\end{array}$ \\
\hline $1 \#$ & \multirow{5}{*}{ Mudstone } & \multirow{3}{*}{ Capillary absorption } & 4.01 & 23.82 & 65.51 & 2.49 \\
\hline $2 \#$ & & & 2.95 & 24.23 & 63.17 & 2.51 \\
\hline $3 \#$ & & & 1.56 & 23.92 & 64.35 & 2.51 \\
\hline $4 \#$ & & \multirow{2}{*}{ Soaking absorption } & 4.01 & 23.94 & 64.35 & 2.51 \\
\hline $5 \#$ & & & 2.90 & 24.06 & 64.50 & 2.51 \\
\hline $6 \#$ & \multirow{2}{*}{ Argillaceous sandstone } & \multirow{3}{*}{ Soaking absorption } & 3.37 & 24.00 & 64.10 & 2.49 \\
\hline 7\# & & & 2.56 & 24.30 & 64.66 & 2.49 \\
\hline 8\# & Sandstone & & 3.34 & 24.20 & 64.42 & 2.46 \\
\hline
\end{tabular}

takes into account the need for surface crack observation (the thinner the sample, the easier the cracks to develop and the easier the observation) and the difficulty of sample preparation (the thinner the sample, the more difficult it is to prepare the sample).

A total of 8 samples were selected for this test, including 5 mudstone samples, 2 argillaceous sandstone samples, and 1 sandstone sample. The basic parameters of each sample are shown in Table 2, and the clay mineral composition is shown in Table 1.

There are many factors influencing the swelling-cracking of expansive rock. The external factors include environmental conditions (temperature and humidity) and water absorption methods (capillary water absorption, soaking water absorption, and pressure). The internal factors include sample size and initial water content, density, clay mineral composition, and internal initial cracks. This test mainly analyzes the influence of initial water content, clay mineral content (different lithology), and different water absorption methods on the characteristics of swelling cracks under no confining condition.

Different initial water content is obtained by controlling the sample to air-dry at $45^{\circ} \mathrm{C}$. Capillary absorption means that the sample absorbs water from the saturated permeable stone through capillary action. Soaking absorption means that the bottom and sides of the sample are immersed in water, and the top surface is left as observation surface without being immersed in water. The samples with the same lithology are all taken from the same rock core to ensure that the samples with the same lithology are uniform.

2.3. Test Device and Process. The soft rock water absorption and cracking test device is shown in Figure 4. The water tank provides the water source to the sample dish, and the sample gains weight by absorbing water. Then, the weight of the water absorbed is measured by the electronic balance, and the photo of swelling cracks on the surface of the sample is obtained with the camera. All collected photos and water absorption data are input to the computer via a data collector.

The main processes of the test are as follows:

(1) Before the test, fix the position of the camera to ensure that the focus direction of the camera is

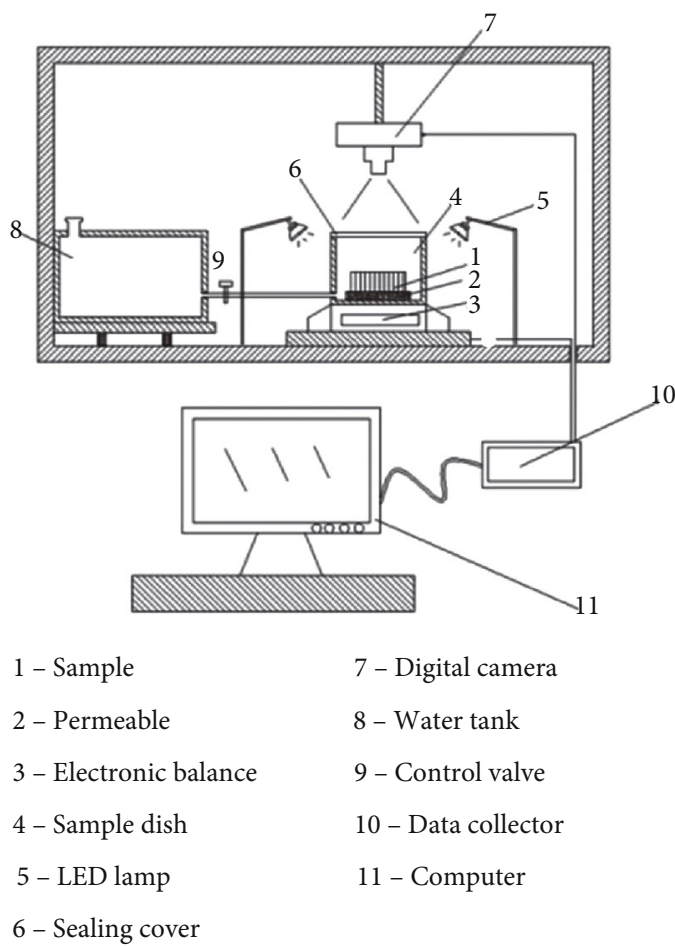

Figure 4: Test device of soft rock water absorption and cracking.

perpendicular to the surface of the sample. At the same time, adjust the LED light sources on both sides to keep the vertical projection as much as possible to reduce the impact of shadows on photo quality

(2) Set the shooting interval of the camera and the recording interval of the electronic balance at the specified time interval

(3) In the capillary moisture absorption mode, pour distilled water into the water tank, and set the sample when the water level in the sample cuvette just surpasses the permeable stone

(4) In the soaking water absorption mode, wrap the surface of the sample with plastic wrap and place it 

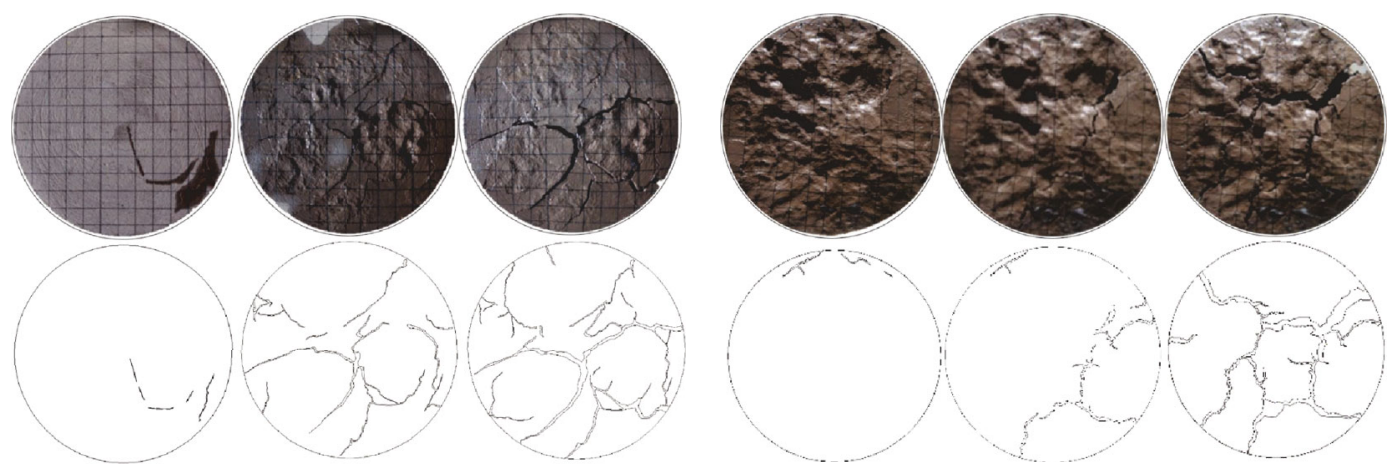

$t=30 \mathrm{~min}$
$w=3.37 \%$

$t=53 \mathrm{~min}$

$t=360 \mathrm{~min}$

$S_{r}=0.20 \%$

$S_{r}=3.68 \%$

\section{$w=8.47 \%$}

$t=30 \mathrm{~min}$

$w=13.02 \%$

$t=143 \mathrm{~min}$

$t=340 \mathrm{~min}$

$S_{r}=8.06 \%$

$S_{r}=0.20 \%$

$S_{r}=3.90 \%$

$w=22.02 \%$

(a) 1\# sample
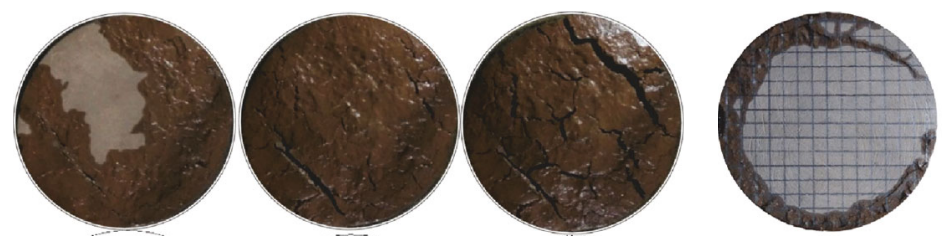

(b) 2\# sample
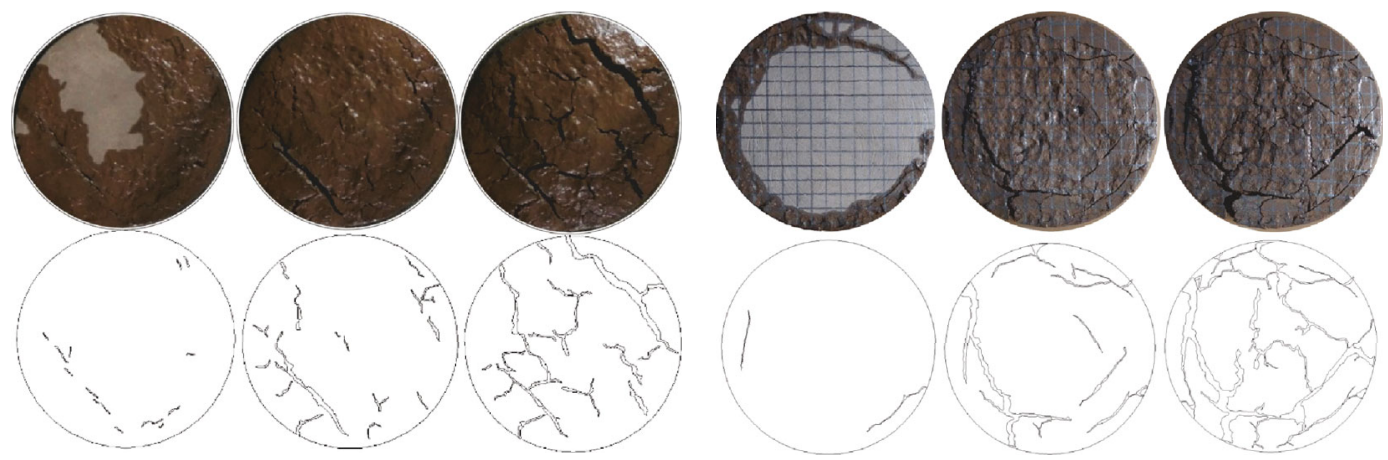

$t=78 \mathrm{~min}$
$w=10.37 \%$
$S_{r}=0.17 \%$

$$
\begin{aligned}
& t=141 \mathrm{~min} \\
& w=18.43 \% \\
& S_{r}=3.45 \%
\end{aligned}
$$

$t=300 \mathrm{~min}$

$w=22.17 \%$

$t=7 \mathrm{~min}$
$w=0.26 \%$
$S=0.24 \%$
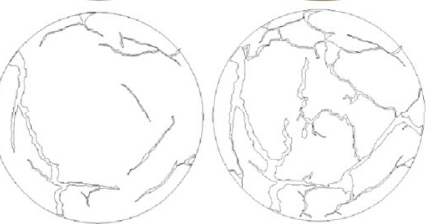

(c) 3\# sample
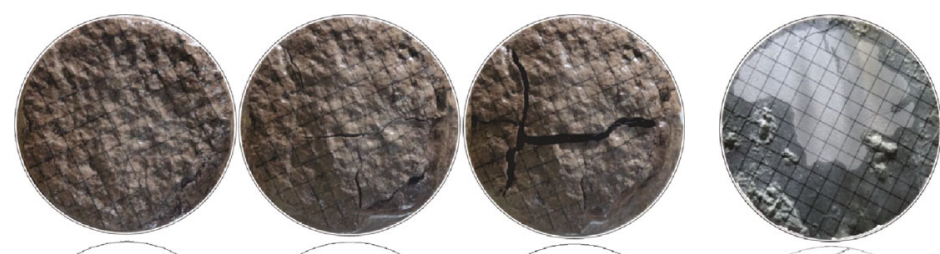

(d) 4\# sample
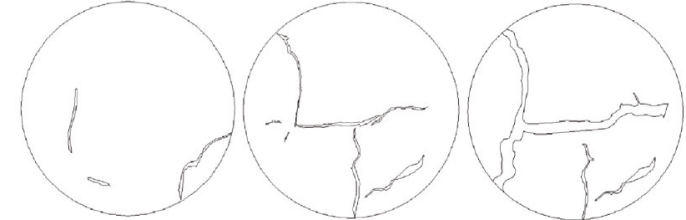

$t=32 \mathrm{~min}$

$t=123 \mathrm{~min}$

$t=157 \mathrm{~min}$

$w=5.20 \%$

$w=10.67 \%$

$w=20.26 \%$

$S_{r}=1.10 \%$

$S_{r}=5.20 \%$

$S_{r}=11.63 \%$

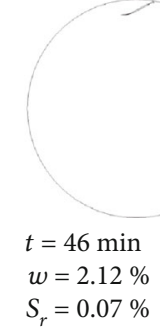

$t=21 \mathrm{~min}$
$w=1.76 \%$

$t=62 \mathrm{~min}$

$S=4.72 \%$

$w=6.68 \%$

(e) 5\# sample

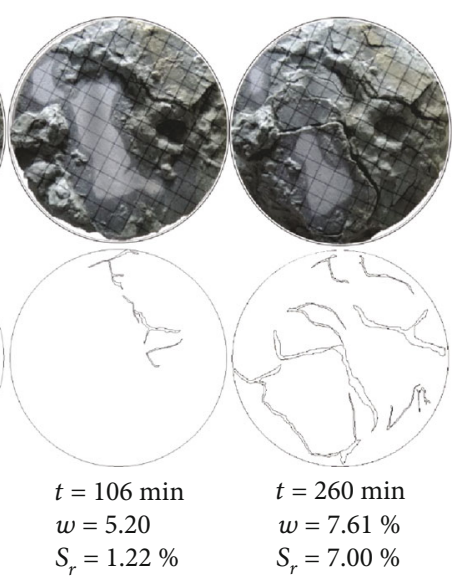

(f) 6\# sample

Figure 5: Continued. 


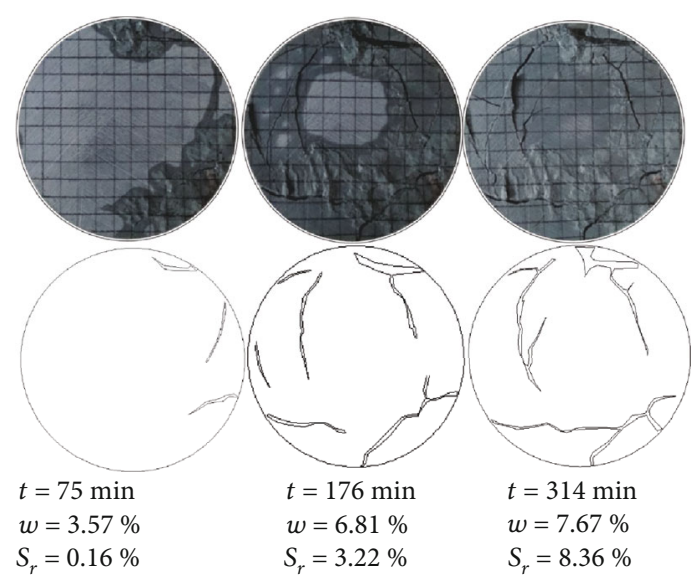

(g) 7\# sample

FIgURE 5: Cracking pictures of samples.

on the permeable stone, and then pour water into the water tank so that the liquid level in the water absorption dish is just under the upper surface of the sample. Close the control valve and remove the sample. Take it out and install the sample after removing the cling film, and open the control valve at the same time

(5) Start collecting test data and observe the test process. When the water absorption does not increase and the cracks no longer change within 1 hour, the test is complete

\section{Experimental Results and Analysis}

3.1. Quantitative Indexes of Crack Field. By taking photos of the surface of the sample during the test, the spatial distribution and temporal changes of the cracks are recorded. Then use image processing technology to get the relevant crack indexes. There are many ways to implement crack image processing. However, considering that the cracks in this test are affected by the background environment (caused by water absorption), it is difficult to perform batch processing in accordance with conventional processing methods [8]. Therefore, the cracks in the photos of this experiment are all manually drawn by CAD. Due to the large amount of photos during the entire experiment, only the images with large fissure changes were processed. In addition, there are many small cracks on the surface of the sample, but due to the influence of swelling and mudding on the mudstone surface, it is difficult to count the small cracks. Therefore, only the cracks with larger width or later development are drawn.

Currently, the more commonly used crack indexes are total length of cracks, average width of cracks, maximum width of cracks, and the proportion of the area of cracks. In this test, the crack degree index was used to quantitatively analyze the evolution of the swelling cracks. This index comprehensively considers the degree of crack development (length and width), and the calculation method is shown in Equation (1).

$$
S_{r}=\frac{\sum S_{i}}{S_{0}},
$$

where $S_{r}$ is the crack degree (\%), $S_{i}$ is the area of the $i$-th crack $\left(\mathrm{mm}^{2}\right)$, and $S_{0}$ is the initial upper surface area of the sample $\left(\mathrm{mm}^{2}\right)$.

3.2. Analysis of Crack Evolution Process. A large number of crack development photos were obtained from the experiment, and crack diagrams at different stages were drawn through CAD. Figure 4 shows the typical photos and crack diagrams of samples $1 \# \sim 7 \#$ at different stages, and lists the state of the sample at each stage, including time $t$, the water absorption $w$, and the crack degree $S_{r}$. Since the 8\# sample did not appear cracks during the water absorption process, it was not analyzed.

It can be seen from Figure 5 that the cracks of the specimens basically developed from the outside to the inside, gradually connected, and developed into a crack network. Each crack network is basically composed of 2 to 4 main fractures and several fine cracks. The basic morphology of the cracks is mainly arc or chord shape which develops circularly and short-line shape which develops radially.

In order to quantitatively analyze the swelling-cracking process of red-bed mudstone, taking the $2 \#$ sample as an example, the curve of the crack degree over time is shown in Figure 6. It can be seen from Figure 6 that the evolution process of the cracks can be divided into three stages, namely, the generation stage, the rapid development stage, and the stabilization stage.

Figure 7 shows the generation stage. During this stage, the sample begins to absorb water, and the surface becomes muddy and uplifted due to swelling and softening. A small amount of fine cracks are generated, but these cracks are 


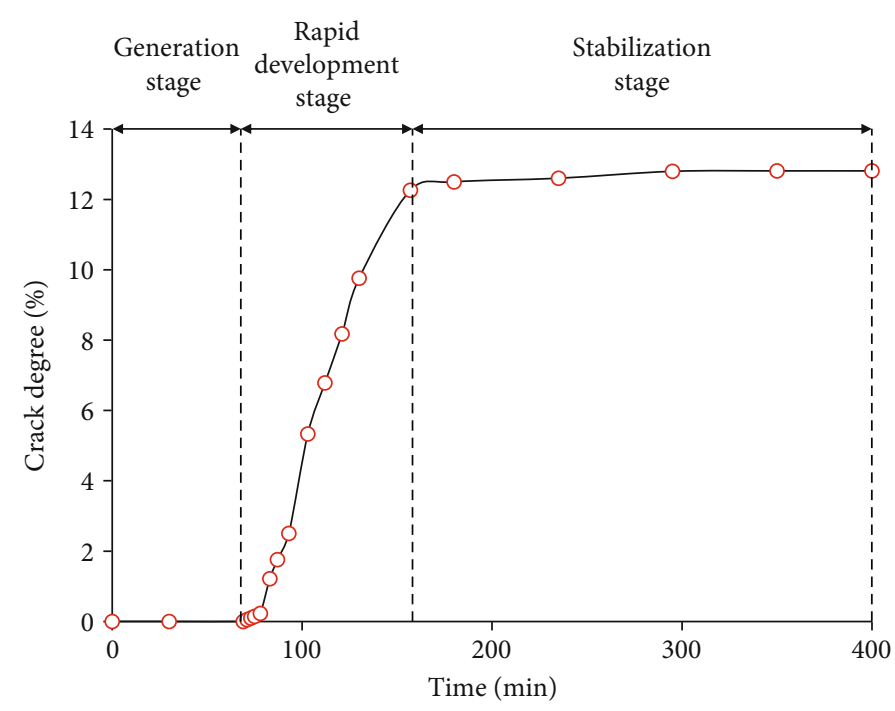

FIgURE 6: Curve of crack degree over time of 2\# sample.
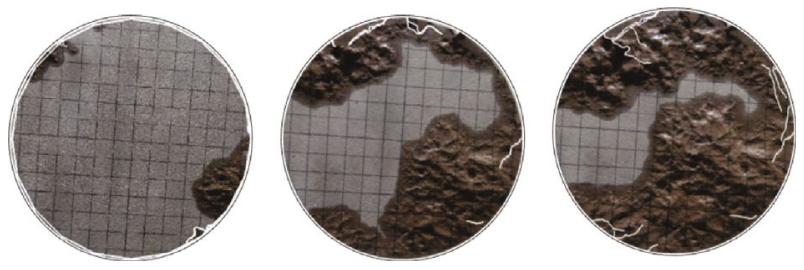

FIGURE 7: Generation stage.

short and local, independent and not connected to each other. The overall crack degree is small.

Figure 8 shows the rapid development stage of the cracks. In this stage, the old small cracks quickly grow and expand with new cracks forming. The old and new cracks are intertwined and connected with each other. In this stage, the crack degree has increased significantly.

Figure 9 shows the crack stabilization stage. During this stage, cracks grow slowly and the crack degree increases slowly to be constant.

3.3. Influencing Factors of Crack Evolution Characteristics. In order to analyze the influence of the initial state of the sample on the evolution characteristics of swelling cracks, plotting the time history curve of crack degree of different water absorption methods and different lithology samples is shown in Figures 10 and 11.

The following points can be obtained from Figures 10 and 11:

(1) The three-stage characteristics of crack development are obvious. In the first stage, the crack degree did not increase. In the second stage, the crack degree increased rapidly. The duration of this stage was short, but the increased crack degree accounted for $90 \%$ of the whole process. In the third stage, the crack degree increased slowly, but eventually stabilized
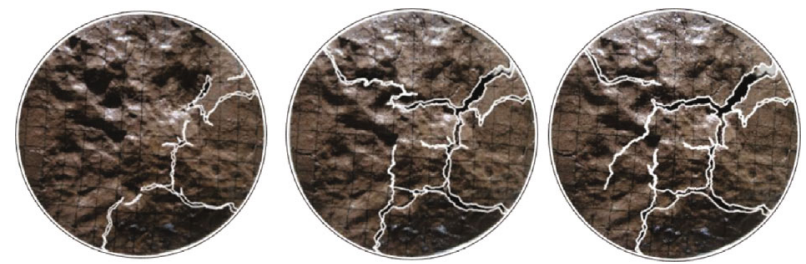

FIgURE 8: Rapid development stage.
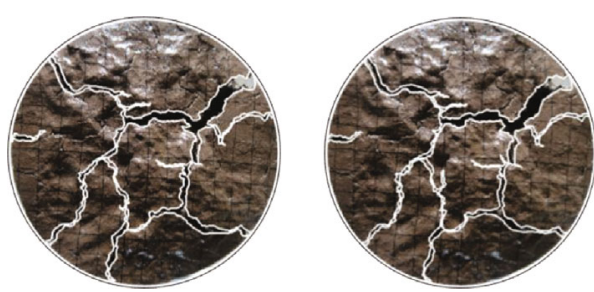

FIgURE 9: Stabilization stage.

(2) Lithology, initial water content, and water absorption methods have a significant impact on the initial cracking time (as shown in Figure 12). Under capillary water absorption, the higher the initial water content of the sample, the earlier the cracks will appear. Under the same initial water content, the initial cracking time of soaking water absorption is significantly earlier than capillary water absorption. Under soaking water absorption conditions, mudstone started to crack earlier than argillaceous sandstone. This phenomenon may be related to the process of water swelling and softening. The initial water content is high, and the initial softening degree of the sample is large; in addition, the content of clay minerals such as montmorillonite is high, the greater the expansion and softening during the water 


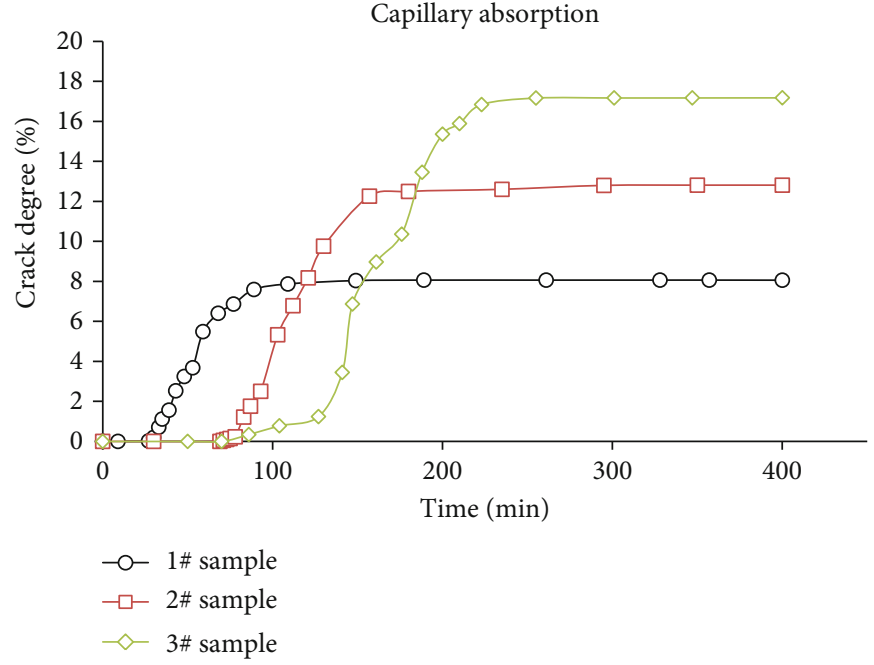

(a)

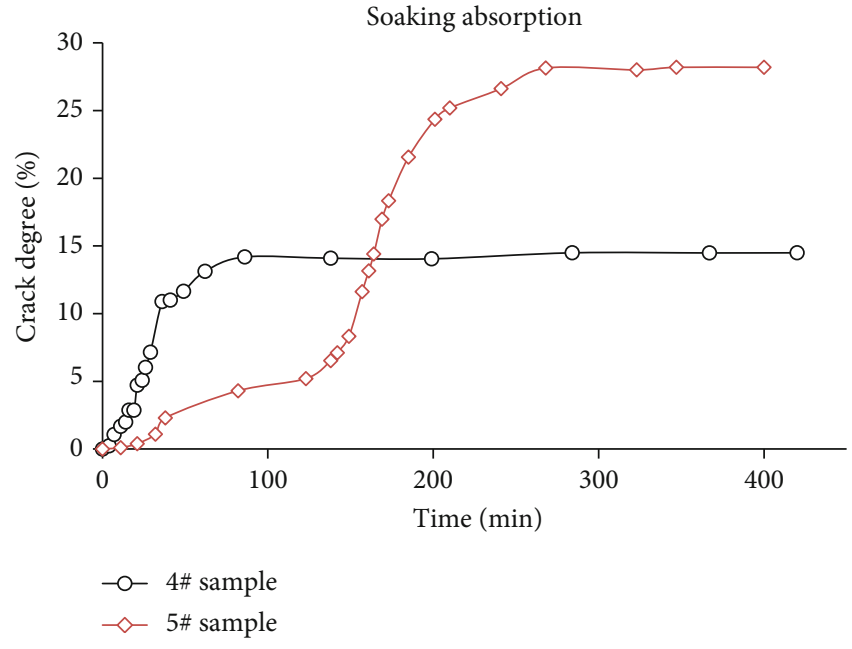

(b)

Figure 10: Time history curves of crack degree of $1 \# \sim 5 \#$ samples.

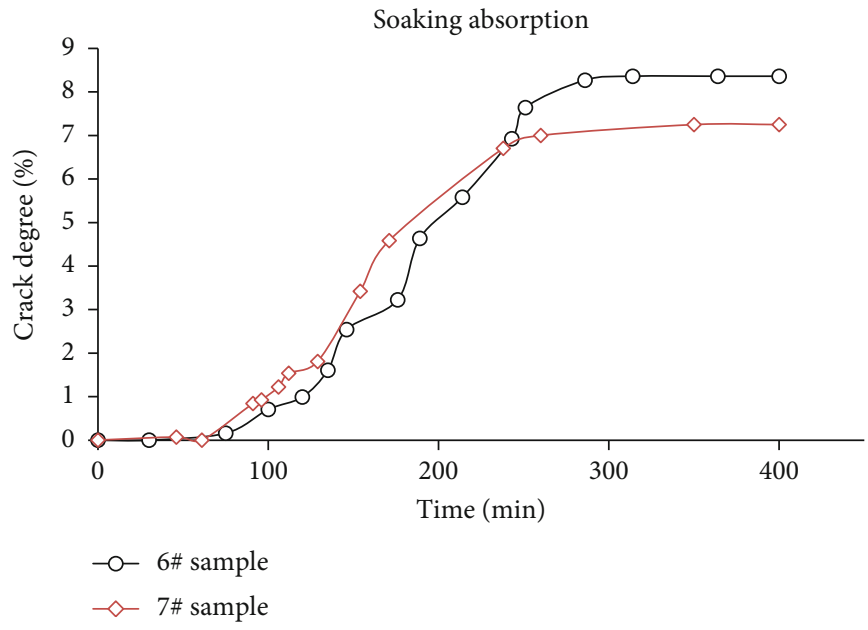

Figure 11: Time history curves of crack degree of 6\# 7\# samples.

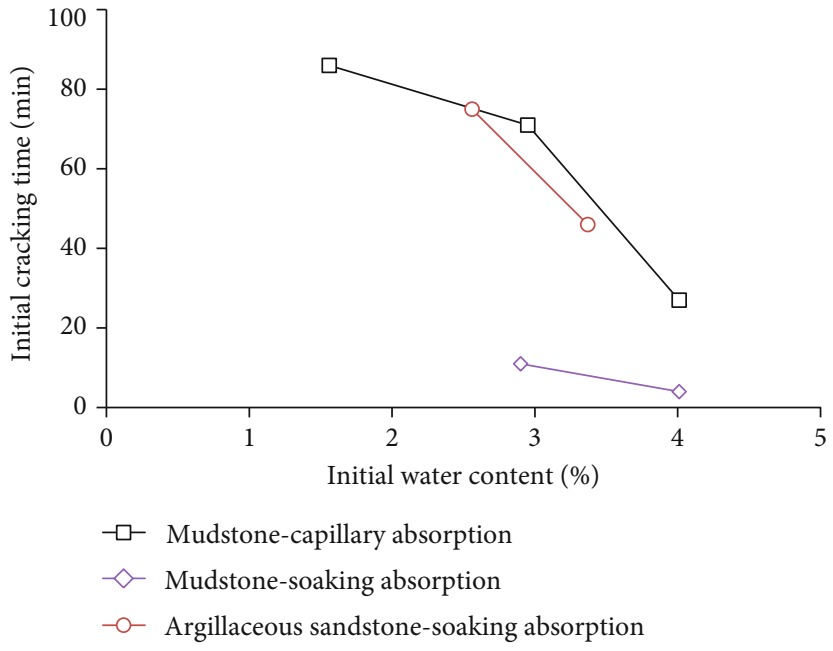

Figure 12: Curves between initial cracking time and initial water content 
TABLE 3: Final crack degree of samples.

\begin{tabular}{|c|c|c|c|c|}
\hline Sample number & Lithology & Method of water absorption & Initial water content (\%) & Final crack degree (\%) \\
\hline $1 \#$ & & \multirow{3}{*}{ Capillary absorption } & 4.01 & 8.06 \\
\hline $2 \#$ & & & 2.95 & 12.81 \\
\hline $3 \#$ & Mudstone & & 1.56 & 17.18 \\
\hline $4 \#$ & \multirow{4}{*}{ Argillaceous sandstone } & \multirow{2}{*}{ Soaking absorption } & 4.01 & 14.50 \\
\hline $5 \#$ & & & 2.90 & 28.20 \\
\hline $6 \#$ & & \multirow{3}{*}{ Soaking absorption } & 3.37 & 7.25 \\
\hline 7\# & & & 2.56 & 8.36 \\
\hline $8 \#$ & Sandstone & & 3.34 & 0 \\
\hline
\end{tabular}

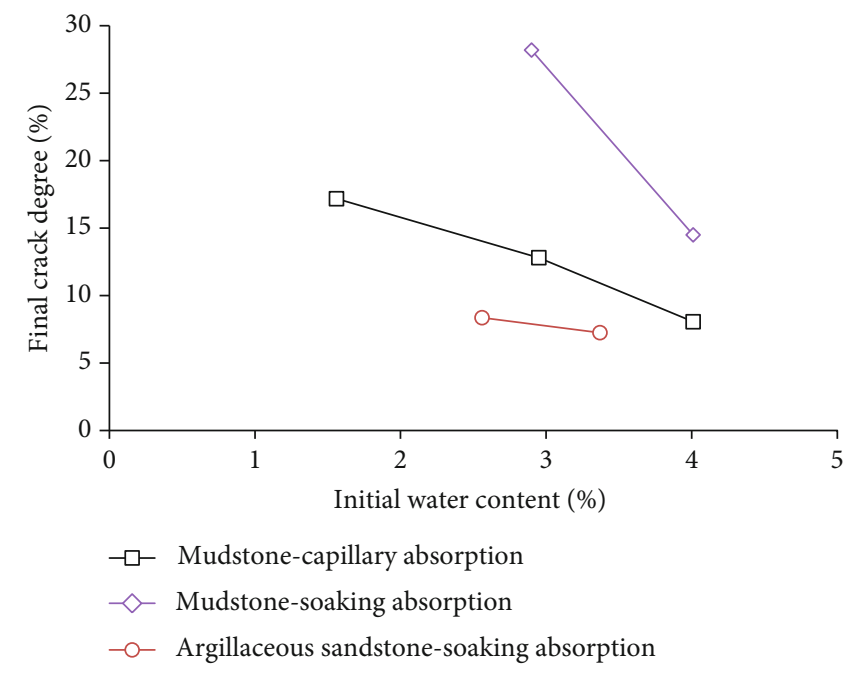

Figure 13: Curves of final fissure ratio and initial water content.

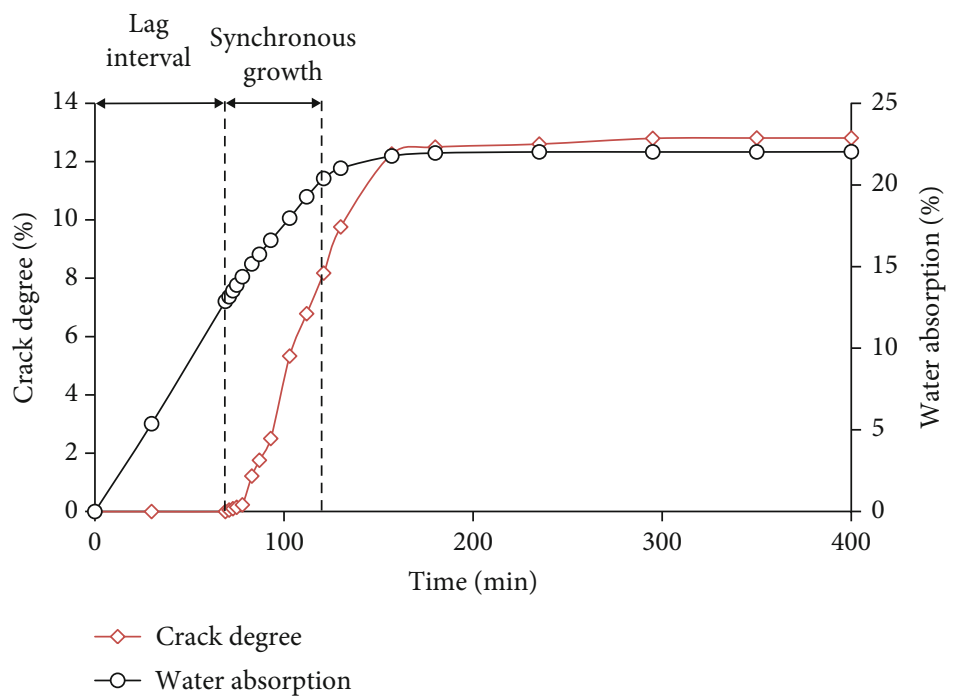

Figure 14: Curves of crack degree and water absorption over time of 2\# sample.

absorption process; finally, the water migration is faster under soaking water absorption. These three reasons work together to make the cracking occurred earlier
(3) Lithology, initial water content, and water absorption methods also have a significant impact on the final crack degree. Table 3 shows the statistical results of the final crack degree after the test, and Figure 13 


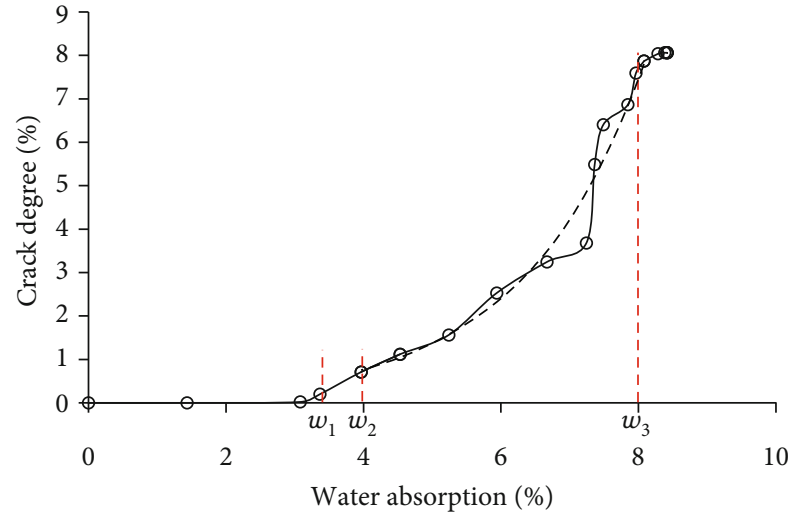

(a) 1\# sample

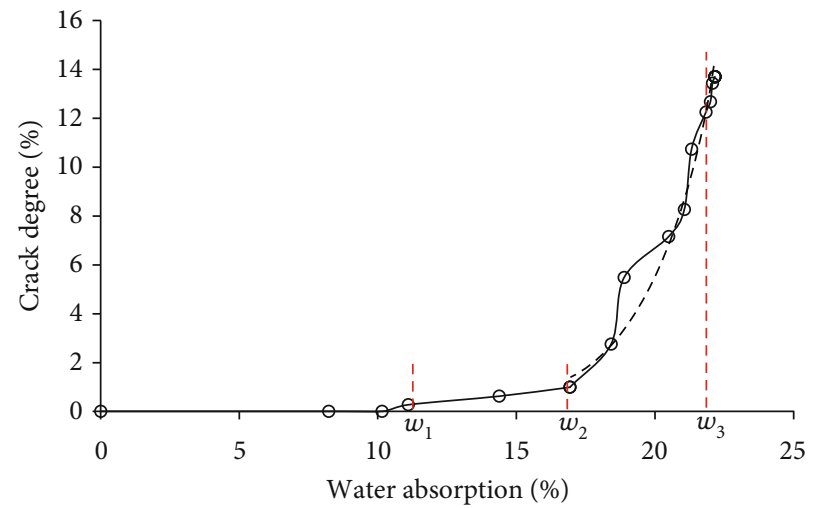

(c) 3\# sample

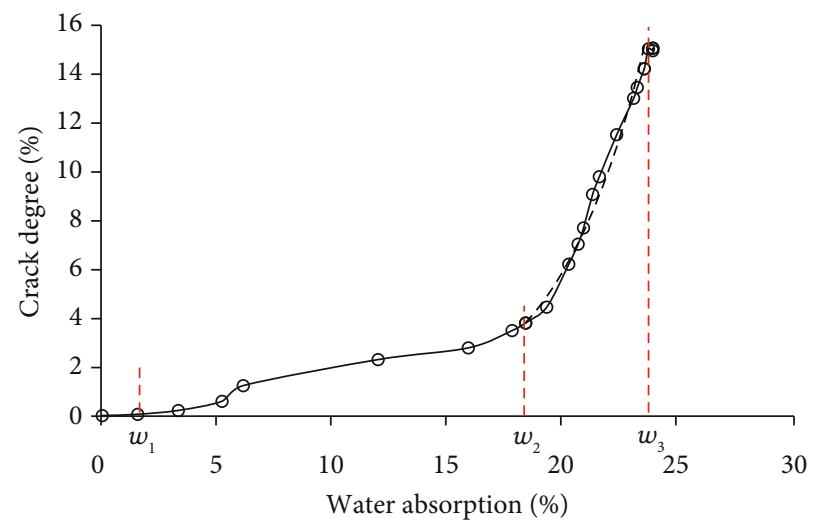

(e) 5\# sample

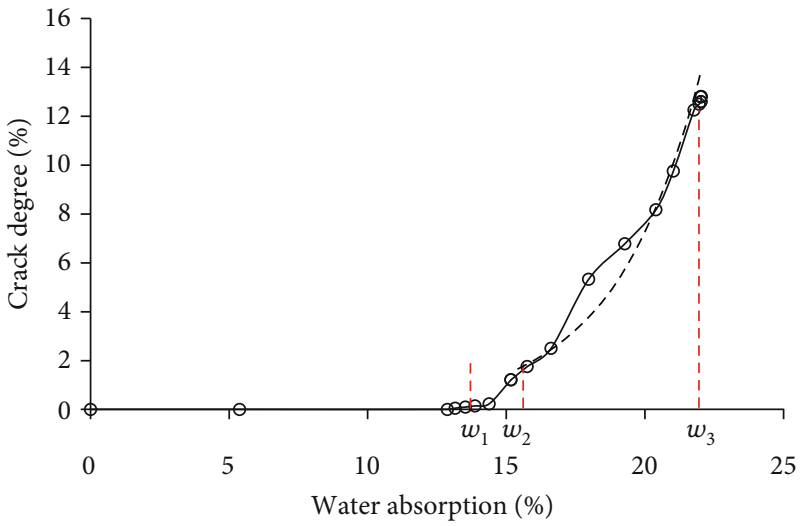

(b) 2\# sample

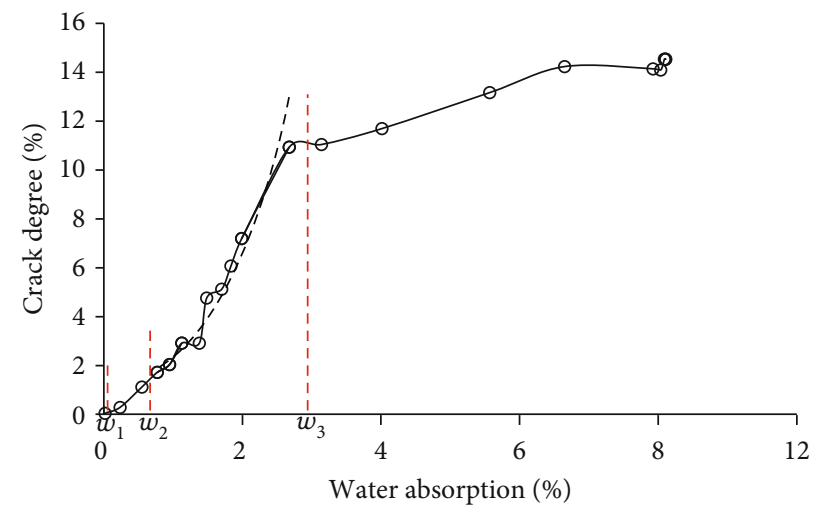

(d) 4\# sample

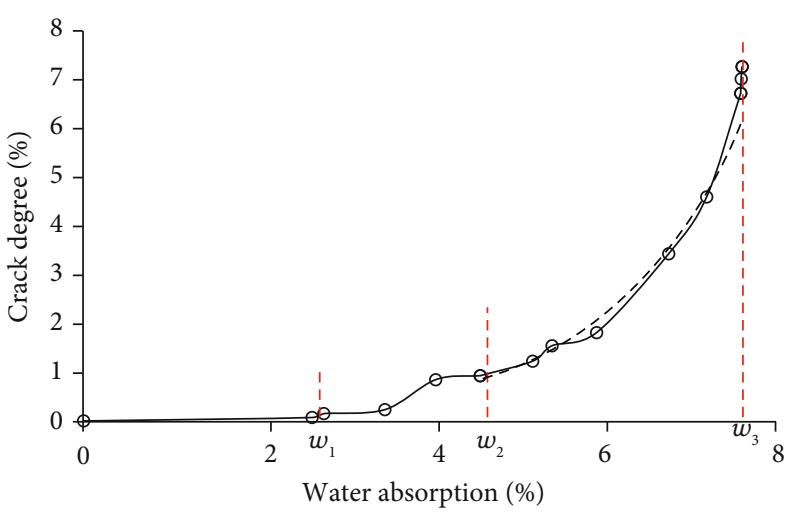

(f) 6\# sample

Figure 15: Continued. 


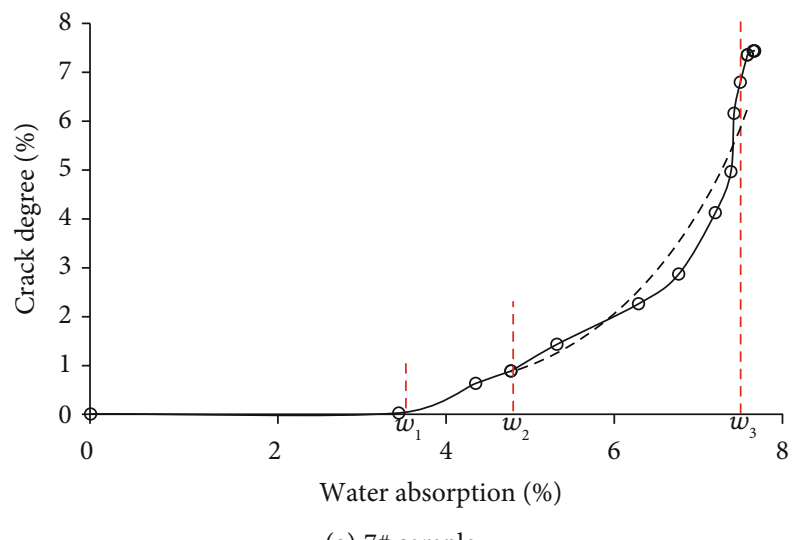

(g) 7\# sample

FIGURE 15: Relationship curves of crack degree and water absorption of 1\# 7\# samples.

TABLE 4: Characteristic values of water absorptions and fitting results.

\begin{tabular}{|c|c|c|c|c|c|c|}
\hline \multirow{2}{*}{ Sample number } & \multicolumn{3}{|c|}{ Characteristic value of water absorptions (\%) } & \multicolumn{3}{|c|}{ Fitting results $\left(S_{r}=a e^{b w}\right)\left(S_{r}(\%), w(\%)\right)$} \\
\hline & $w_{1}$ & $w_{2}$ & $w_{3}$ & $a$ & $b$ & $R^{2}$ \\
\hline $1 \#$ & 3.08 & 3.97 & 8.29 & 0.0791 & 0.5683 & 0.98 \\
\hline $2 \#$ & 13.15 & 15.12 & 22.02 & 0.0119 & 0.3207 & 0.97 \\
\hline $3 \#$ & 11.10 & 16.94 & 21.86 & 0.0009 & 0.4468 & 0.95 \\
\hline $4 \#$ & 0.26 & 0.91 & 3.76 & 0.8509 & 0.8527 & 0.95 \\
\hline $5 \#$ & 1.54 & 18.38 & 23.71 & 0.0517 & 0.2687 & 0.98 \\
\hline $6 \#$ & 2.64 & 4.59 & 7.61 & 0.043 & 0.6509 & 0.99 \\
\hline 7\# & 3.56 & 4.87 & 7.67 & 0.0283 & 0.7253 & 0.96 \\
\hline
\end{tabular}

shows the relationship between the final crack degree and the initial water content

It can be seen from Figure 13 that the lower the initial water content, the greater the final crack degree of the sample, and the final crack degree under the soaking water absorption method is greater than the capillary water absorption. The final crack degree of mudstone is greater than that of argillaceous sandstone and sandstone.

The main reason for the development and expansion of swelling cracks is the uneven expansion of the sample during water absorption. The degree of this uneven expansion is controlled by the swelling potential of expansive rock.

The greater the swelling potential of the expansive rock is, the greater the internal stress caused by the uneven swelling deformation, and the resulting crack development and expansion will be more intense. The mudstone sample contains $20 \%$ montmorillonite, and its expansion potential is much greater than that of argillaceous sandstone, while sandstone has no montmorillonite mineral and has no obvious expansibility. Therefore, the swelling crack degree is generally larger than that of sandy mudstone. Due to the small expansibility of sandstone, the uneven expansion stress generated is not enough to cause the damage of the rock material, so no cracks are generated.

Even with the same expansion potential (such as 1 3\# samples, 4 5\# samples, and 6 7\# samples), the initial water content of the sample is different, and the expansion energy released under the condition of complete water absorption is also different. The lower the initial water content is, the greater the released expansion energy is, and the greater the swelling deformation and swelling stress are. Therefore, as the initial water content decreases, the final crack degree increases.

The water absorption method also affects the crack development of the sample. Compared with the capillary method, the sample absorbs water faster under the soaking method. Thus, the faster the water absorption is, the larger the internal water content gradient is, resulting more serious uneven expansion and softening. Therefore, the final crack degree under soaking method is higher than capillary method.

In summary, the degree of development of swelling cracks in expansive rocks is controlled by the swelling potential, and the basic material condition for swelling and cracking is swelling clay minerals.

3.4. Analysis of the Relationship between Crack Degree and Water Absorption. The swelling and cracking of red-bed mudstone is a process in which water absorption gradually increases, expansion occurs continuously, and cracks continue to develop. In order to analyze the time history change relationship between the crack degree and the water absorption in this process, the time history change curve of the $2 \#$ sample crack degree and water absorption was drawn in the same coordinate, as shown in Figure 14. 


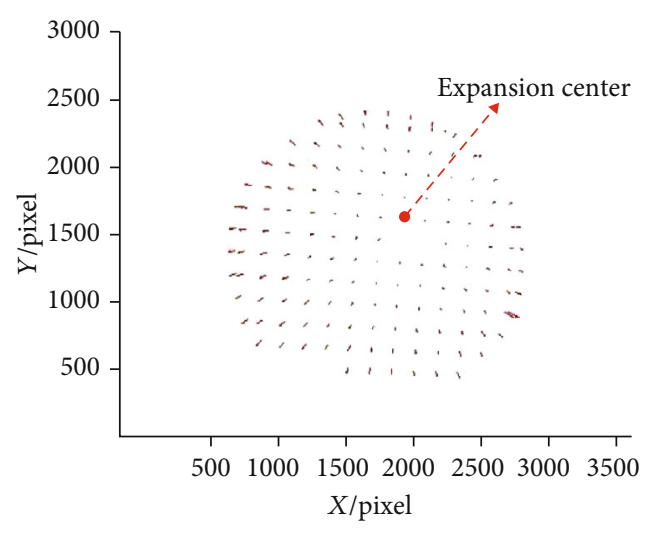

(a) $t=19 \mathrm{~min}$

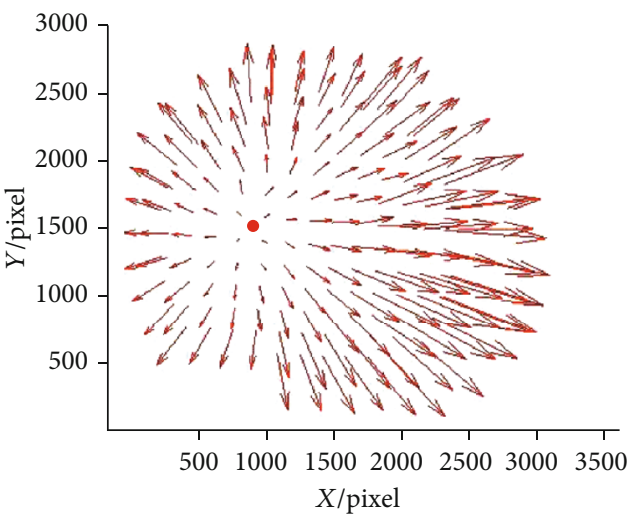

(c) $t=88 \mathrm{~min}$

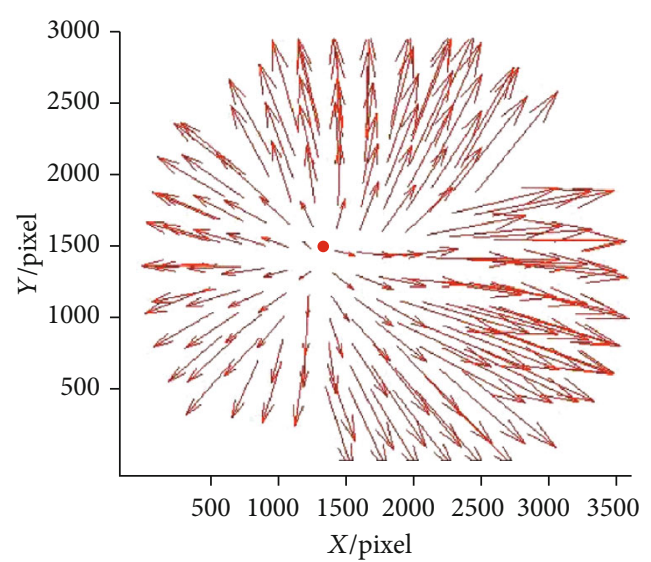

(e) $t=158 \mathrm{~min}$

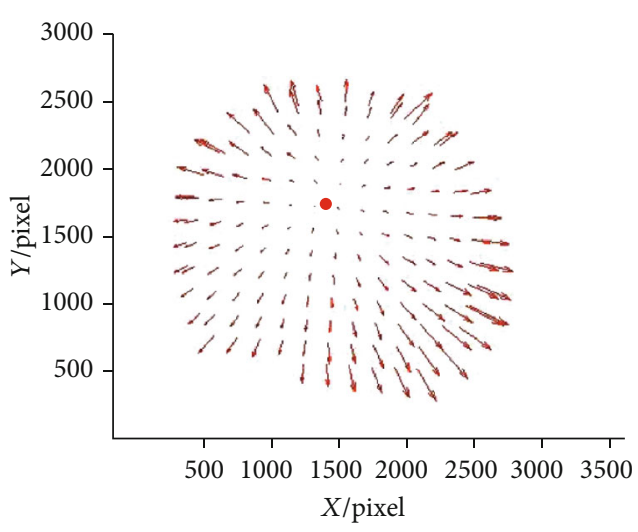

(b) $t=46 \mathrm{~min}$

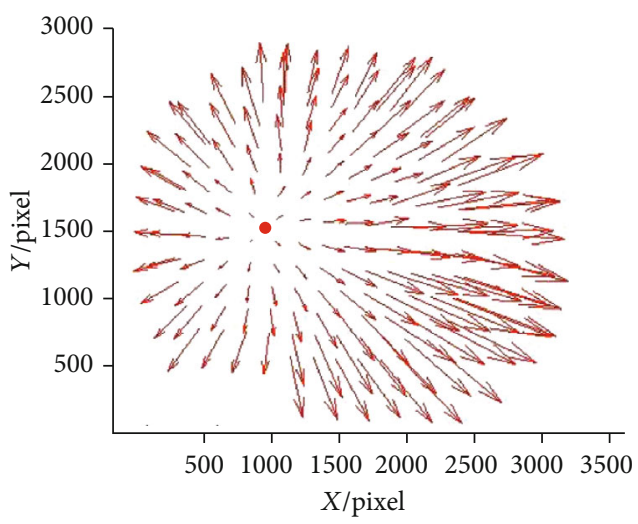

(d) $t=94 \mathrm{~min}$

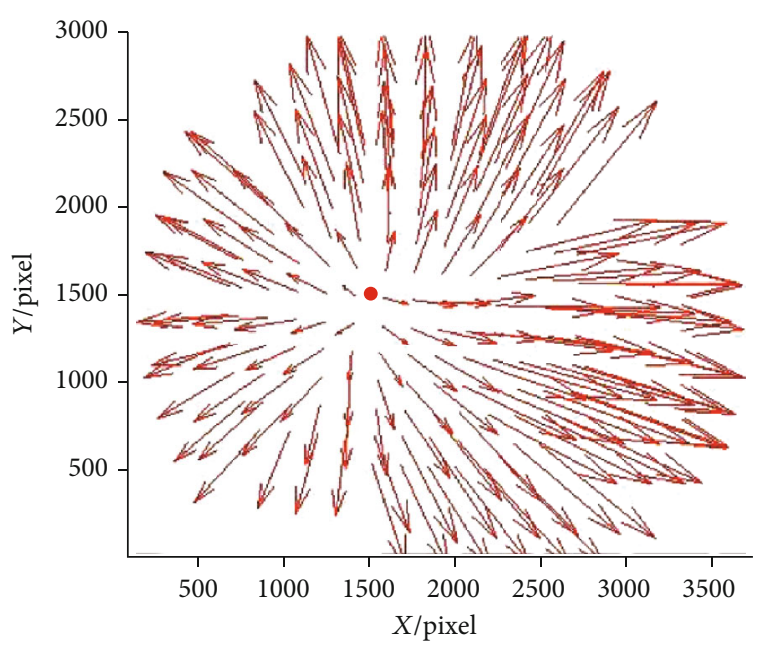

(f) $t=236 \mathrm{~min}$

Figure 16: Displacement vector graph in different times of 2\# sample.

It can be seen from Figure 14 that the crack degree is basically unchanged in the early stage of the test, while the water absorption increases rapidly. When the water absorption reaches a certain level, the cracks and the water absorption increase simultaneously. After the growth of water absorption gradually slows to stability, the cracks still grow, but eventually tend to stabilize. In general, the growth of the crack degree lags behind the increase of water absorption.
In order to further analyze the relationship between the crack degree and water absorption, the relationship curves of $1 \# \sim 7 \#$ samples are plotted in Figure 15. It can be seen from Figure 15 that the crack degree of the seven samples changes with the water absorption basically similar, and there are three characteristic values of water absorption that control the development of the cracks. At the beginning of the test, the water absorption continued to increase, but the crack degree was always zero. When the water absorption increases 


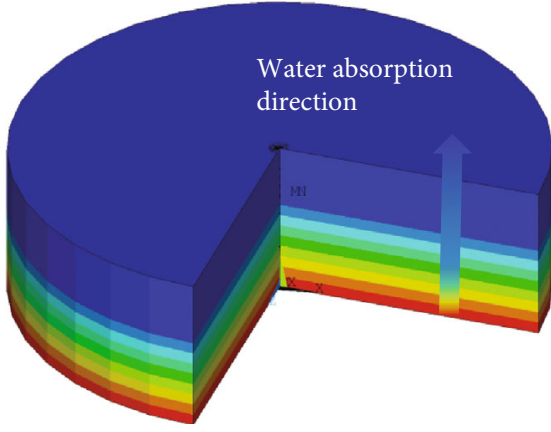

(a) Capillary absorption

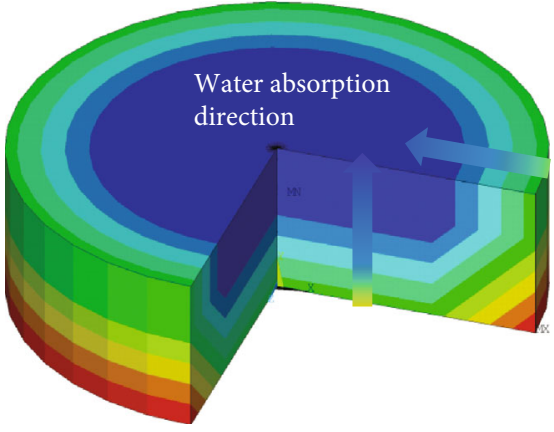

(b) Soaking absorption

FIGURe 17: Numerical analysis model.
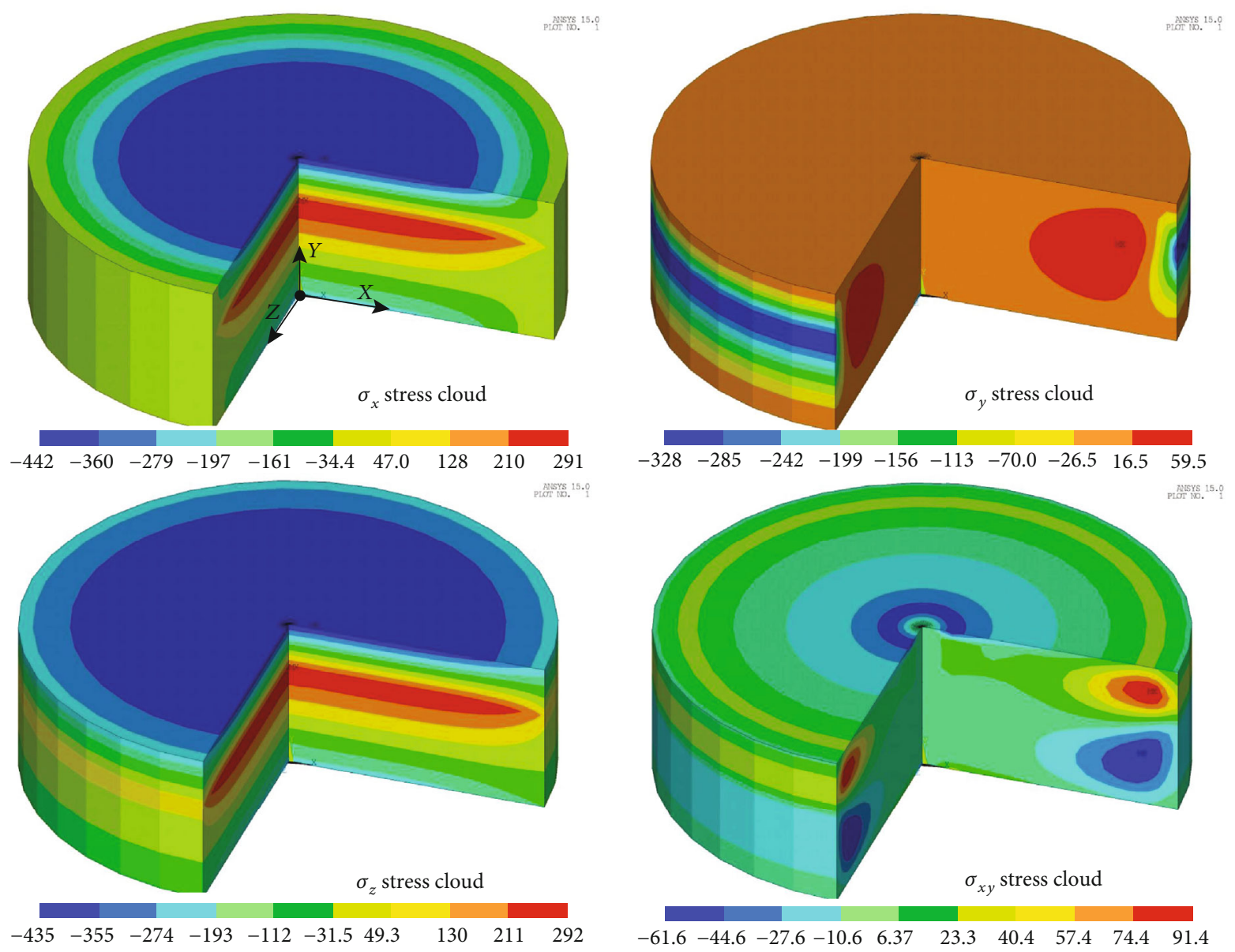

FIGURE 18: Stress cloud diagrams under capillary water absorption (unit: $\mathrm{kPa}$ ).

to the first characteristic value $w_{1}$, cracks begin to occur, and the crack degree slowly increases with the water absorption. As the water absorption increases to the second characteristic value $w_{2}$, the crack degree begins to increase sharply with the water absorption. The growth trend is close to the exponential type, and the fitting correlation is good $\left(R^{2}>0.9\right)$. When the water absorption is close to or reaches the third characteristic water absorption $w_{3}$, the crack degree increases slowly to a stable value. Table 4 lists the characteristic values of water absorption of each sample and the fitting results of the rapid development stage.

Among the three characteristics of water absorption, $w_{2}$ has a relatively large engineering significance. Under rainfall conditions, with the infiltration of water, the water absorption of swelling rock/soil slopes gradually increases. When the water absorption increases to $w_{2}$, the cracks on the open surface such as the toe or shoulder of the slope will develop rapidly. As a result, the overall strength of the slope shoulder, 

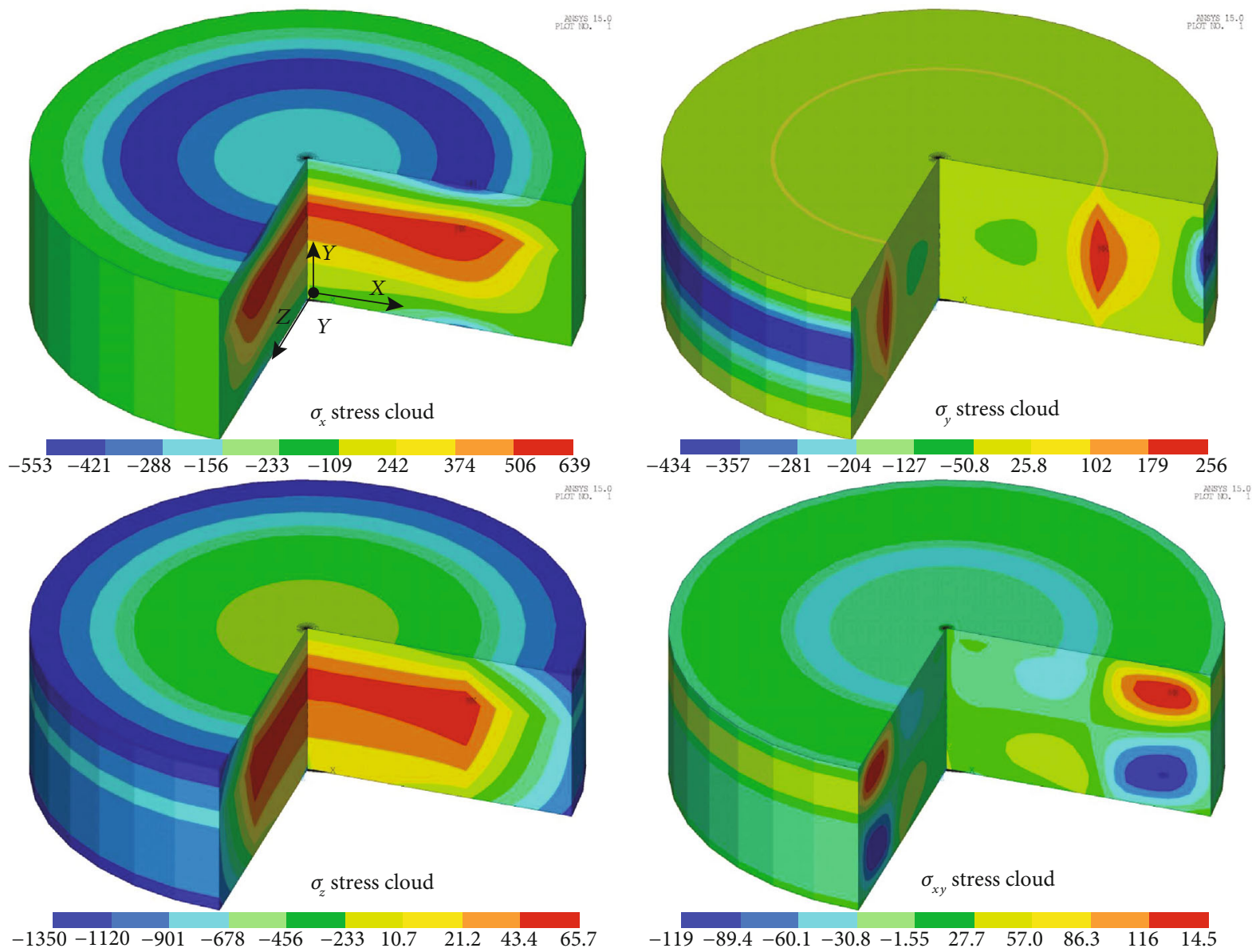

FIGURE 19: Stress cloud diagrams under soaking water absorption (unit: kPa).

especially the slope toe, is significantly reduced, leading to instability and failure of the slope.

\section{Discussion on the Swelling-Cracking Mechanism}

In the process of water loss and shrinkage of expansive rock/soil, tensile stress is generated on the surface due to the different evaporation degrees of the external and internal surfaces. When the tensile stress exceeds the tensile strength of the soil, tensile cracks will occur. The tensile stress caused by this inconsistent water loss of internal and external will make the cracks continue to develop in depth, and the cracks will develop and expand horizontally with the overall water loss and shrinkage of the soil. However, different from shrinkage cracks, swelling cracks of expansive rock are generated in the process of water absorption and swelling. In this process, on the one hand, the uneven expansion deformation leads to the internal swelling stress; on the other hand, the water swelling and softening decrease the bond strength between clay particles. From these two aspects, the swelling-cracking mechanism is completely different from the shrinkage cracking mechanism, so the mechanical mechanism of the swelling and cracking needs to be further studied.
4.1. Reasons for Uneven Expansion of Swelling Rock. In order to intuitively reflect the uneven expansion of the swelling rock during the water absorption process, the displacement of the black grid points in the $2 \#$ sample was calculated, and the displacement vector diagram is drawn in Figure 16.

It can be seen from Figure 16 that during the process of water absorption, the sample continuously expands outwards, and there is always a point in each vector diagram that does not shift, which is regarded as the center of expansion. As time changes, the center of expansion is constantly changing and it is not near the center of the sample. This shows that the water swelling process is an uneven expansion, and this uneven expansion is constantly changing over time.

The swelling potential of expansive rock is directly related to its clay mineral content, and the release of swelling potential is controlled by its water absorption. Therefore, from these two aspects, the uneven expansion of the sample may be caused by uneven water absorption and uneven distribution of swelling clay minerals.

4.2. Uneven Water Absorption Process. The process of water migration inside the sample inevitably determines the unevenness of water absorption. In the process of water absorption for a uniform and crack-free sample, the outer material preferentially absorbs water and expands. With the migration of water, the inner material expands later, so there 


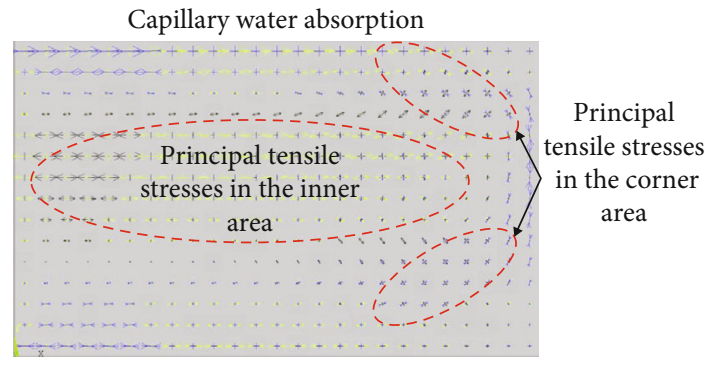

(a)

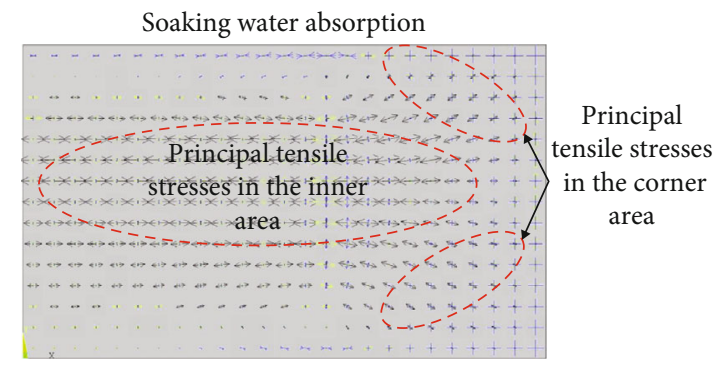

(b)

FIgURe 20: Principal stress vector diagram of XOY section.

is a sequential expansion difference in time. At the same time, the external has larger water absorption than the internal, meaning the released expansion energy of the external is greater than that of the internal. Therefore, there is an uneven expansion in space. In general, due to uneven water absorption, there is a humidity gradient field in the sample space, and the humidity gradient field changes with time.

In order to analyze the distribution law of the expansion stress caused by the humidity gradient field, an axisymmetric numerical analysis model was established using ANSYS software, as shown in Figure 17. The material parameters involved in the model refer to Dai et al. [29], and the calculated stress cloud diagrams are shown in Figures 18 and 19 (the $X$-axis is the radial direction, the $Y$-axis is the axial direction, and the $Z$-axis is the circular direction).

It can be seen from Figures 17 and 18 that the stress distribution law is basically similar in the two cases of soaking and capillary water absorption. The radial stress and the circular stress $\sigma_{z}$ have similar distributions, and both change more uniformly along the radial direction. The outer area is compressive stress; the middle area is tensile stress. Axial stress $\sigma_{y}$ changes from compressive stress to tensile stress from outside to inside in the radial direction, with obvious concentrated stress area. The shear stress $\sigma_{x y}$ has an obvious concentration area in the outer edge, and the whole internal shear stress is much smaller than other stresses.

Since the internal area of the sample has not been softened by water, the horizontal tensile stress $\sigma_{x}$ and $\sigma_{z}$ needs to destroy the bond strength to produce vertical cracks. This is difficult when there is no internal water swelling and softening, and no structural defects (such as microcracks). The concentrated area of axial stress $\sigma_{y}$ is on the outer surface, and prone to water softening. Therefore, this area is easier to damage and crack from the perspective of fracture mechanics. In addition, from the principal stress vector diagram of the $X O Y$ section (Figure 20), there are principal tensile stresses in the inner area and corner area of the specimen, which may provide mechanical conditions for the propagation of the cracks.

According to the above analysis, the sample swells during the process of water absorption, and compressive stress concentration area appears in the middle part of the side (see Figure 21). Due to compressive stress concentration $\sigma_{y}$ and water softening of the rock material, shear failure is very

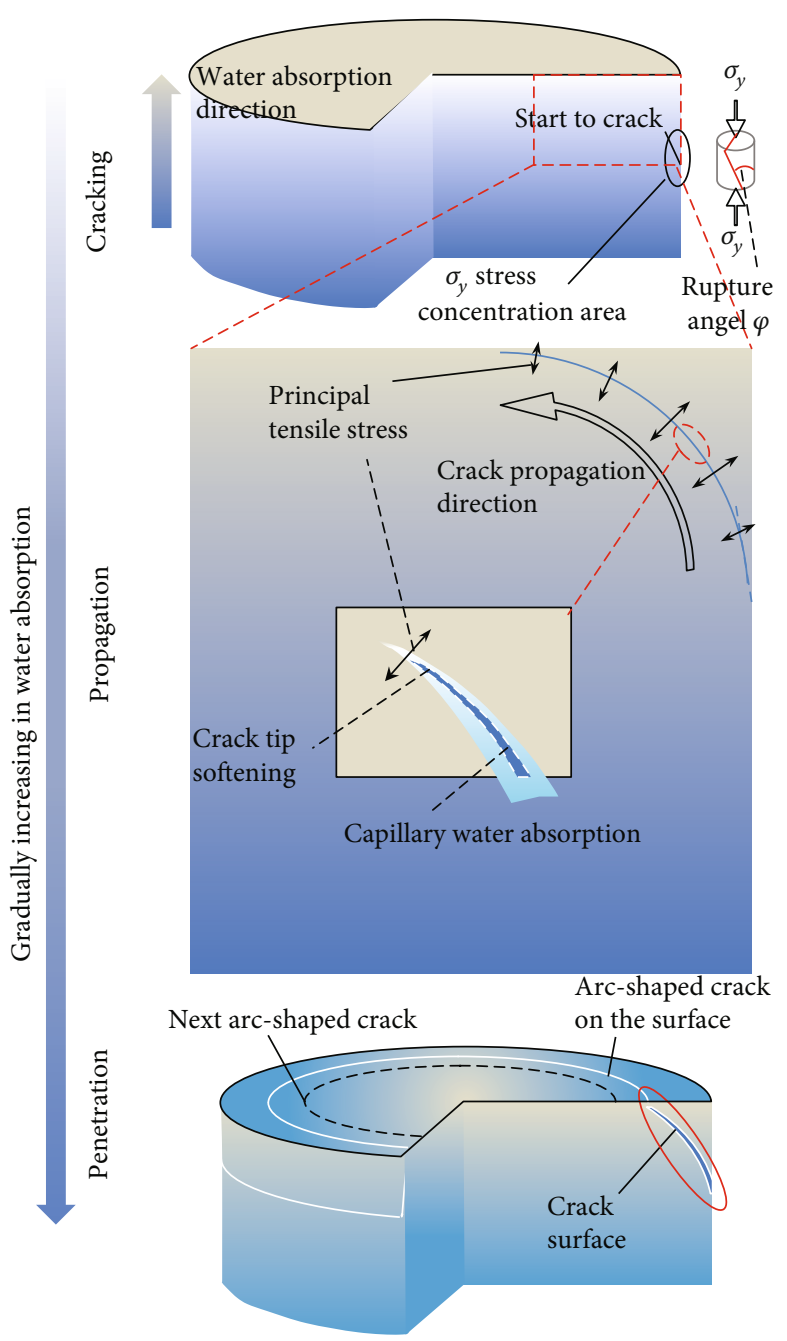

Figure 21: Processing of crack development.

likely to occur in this area, and the crack will form a certain angle (rupture angle $\varphi$ ) with the side face. Under capillary action, water will migrate to the tip of the crack, causing the tip to absorb water and soften. At the same time, under the action of the principal tensile stress in the corner area, the crack will continue to expand along the vertical direction of the principal tensile stress until it penetrates the upper surface of the sample, forming a crack surface as shown in 


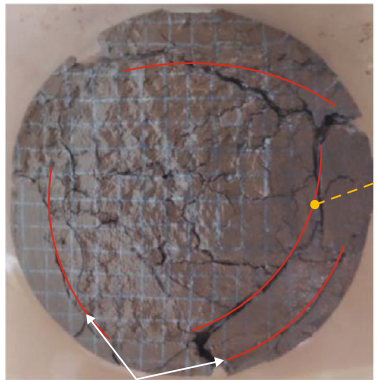

Arc-shaped cracks on the surface

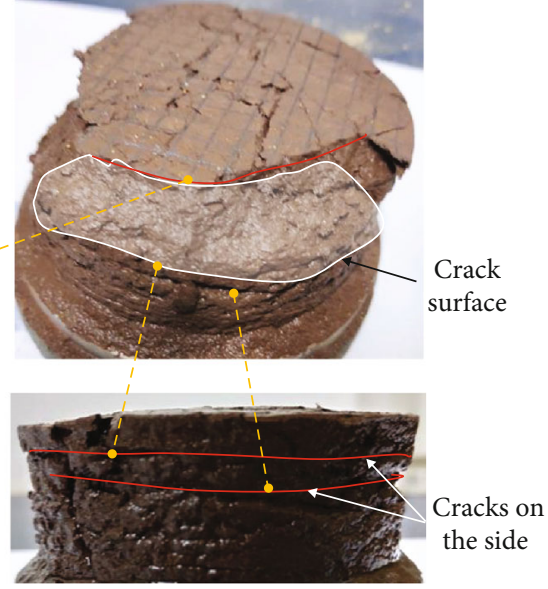

Figure 22: Cracks of 4\# sample.
Figure 21. It is worth noting that, theoretically, this kind of crack can develop on the upper and lower surfaces, and the degree of softening and crack development on the lower surface should be more serious. But in fact, due to the friction between the bottom surface and the permeable stone and the action of gravity, the degree of development of cracks on the bottom surface is much lower than that on the upper surface.

The development mode of this crack will gradually move to the inside of the sample as the crack penetrates and softens by water absorption. In this way, during the whole test process, the sample will produce layer after layer of "wrapped" crack surface, which is a layer of arc-shaped cracks when observed on the surface of the sample. This type of arcshaped cracks appears more often in the rapid development stage (Figure 22).

Finally, the model considers the case where the material is uniform and has no internal microcracks. In fact, according to the SEM results (Figure 2), it can be seen that there are obvious microcracks in the sample. These microcracks are fast passages for water swelling, aggravating the uneven degree of swelling and deformation. In addition, the cracks are also the locations of poor cementation inside the rock mass. Under the action of internal horizontal tensile stress and water softening, the microcracks will stretch and expand in the vertical direction, and the tendency of the cracks to develop is perpendicular to the direction of the horizontal principal tensile stress. After the microcracks expand to penetrate the surface, a visible chord-like macrocrack is formed, as shown in Figure 23.

4.3. Uneven Distribution of Swelling Clay Minerals. During the test, the surface of mudstone and argillaceous sandstone showed obvious mudding and uneven uplift (Figure 24). This indicates that the clay minerals in the sample are not evenly distributed. The degree of unevenness may be related to the size and distribution of clay particles and the composition of clay minerals during mudstone deposition.

The content of clay minerals in different areas of the sample is different, and the final water content of different areas will also be different under the condition of sufficient water

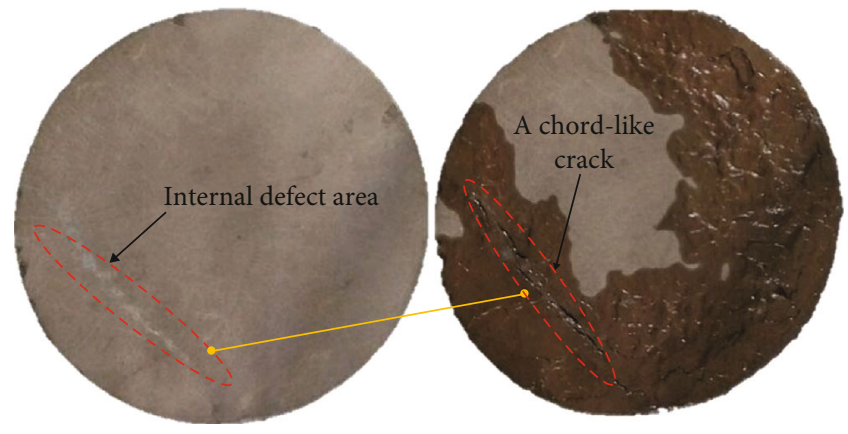

FIGURE 23: Surface chord cracks of 3\# sample.

supply. Therefore, the sample after the test is divided into the upper layer and the bottom layer. The upper layer is divided into different areas with the cracks as the boundary to measure the water content, as shown in Figure 25 (take 2\# sample as an example). Table 5 records the results of final water content in different areas of $1 \# \sim 7 \#$ samples. The crack network of each sample is different, and the number (5 6) and size of the regions divided by the cracks are also different. It can be seen from Table 4 that the water content of different areas of the same sample is different. 1\#, 3\#, and $4 \#$ samples have relatively small differences in water content of different areas, while $2 \#$ and $6 \#$ have great differences. $2 \#$ is the difference between the upper and lower layers, while $6 \#$ is the overall difference, and its range is the largest, reaching 34.4\%.

The uneven distribution of clay minerals on the one hand leads to differences in the degree of water absorption; on the other hand, it also leads to differences in swelling potential. Therefore, it is more likely to cause uneven expansion of the rock and aggravate the development and expansion of cracks. Especially when the internal clay mineral content of the sample is greater than the external one, the internal water swelling pressure is greater than the external one, resulting in external tension. And the outside is an easy-softening zone, which makes it easier to produce vertical tension cracks. With water absorption and softening, the cracks gradually develop inward along the radial direction. 

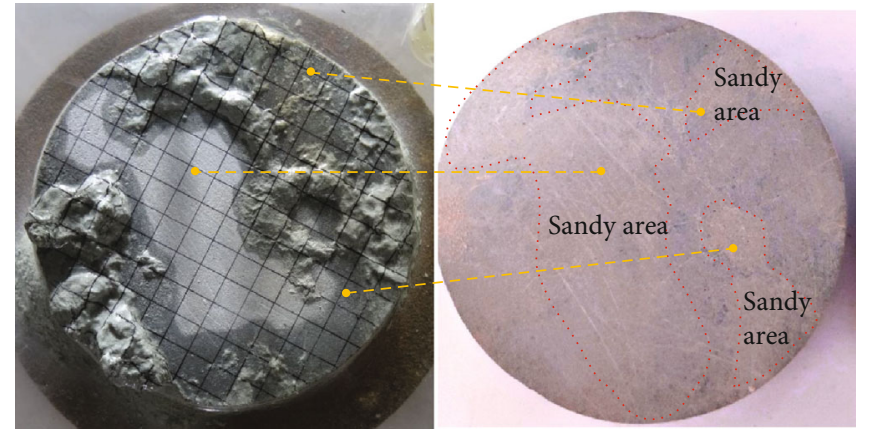

FIgURE 24: Uneven expansion on the surface of 6\# sample.

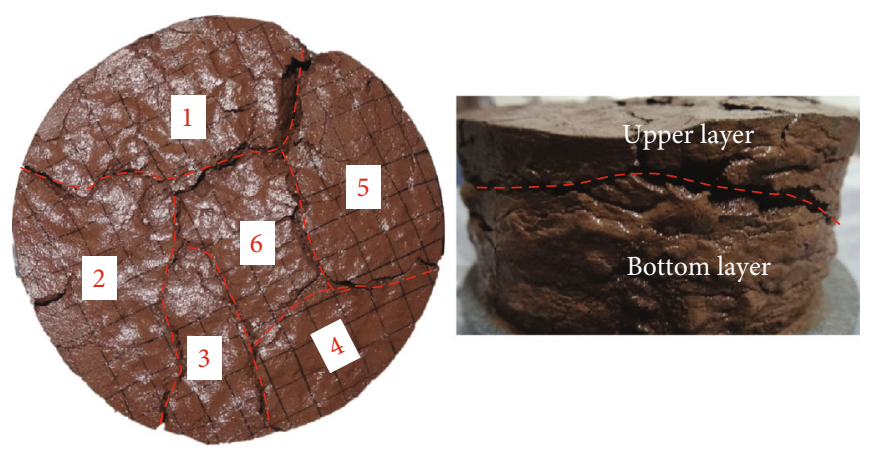

FigURE 25: Measuring water content of 2\# sample.

TABLE 5: Water content in different areas (unit: \%).

\begin{tabular}{|c|c|c|c|c|c|c|c|c|c|}
\hline \multirow{2}{*}{ Sample number } & \multicolumn{6}{|c|}{ Distribution area } & \multirow{2}{*}{ Bottom layer } & \multirow{2}{*}{ Average value } & \multirow{2}{*}{ Range } \\
\hline & 1 & 2 & 3 & 4 & 5 & 6 & & & \\
\hline $1 \#$ & 11.20 & 11.86 & 12.43 & 12.29 & 13.00 & 12.69 & 15.21 & 14.51 & 4.01 \\
\hline $2 \#$ & 25.78 & 24.26 & 34.89 & 33.23 & 29.02 & 14.40 & 24.96 & 25.70 & 20.5 \\
\hline $3 \#$ & 32.70 & 31.35 & 29.74 & 27.34 & 29.67 & - & 27.35 & 28.60 & 5.36 \\
\hline $4 \#$ & 16.70 & 14.08 & 15.63 & 14.81 & 17.14 & - & 15.25 & 15.36 & 3.06 \\
\hline $5 \#$ & 27.40 & 26.49 & 35.20 & 32.03 & 31.60 & - & 31.62 & 31.46 & 8.71 \\
\hline $6 \#$ & 28.40 & 8.53 & 20.74 & 29.14 & 27.16 & 39.73 & 5.35 & 9.70 & 34.4 \\
\hline $7 \#$ & 12.97 & 11.33 & 9.14 & 11.49 & 11.78 & 10.62 & 8.69 & 9.32 & 4.28 \\
\hline
\end{tabular}

Based on the above analysis, the swelling rock absorbs water and expands unevenly, causing internal swelling stress. Under the effect of structural defects such as internal microcracks and water softening, the expansion stress will destroy the internal structure, resulting in the generation and expansion of cracks. This uneven expansion is mainly caused by uneven water absorption and uneven distribution of clay minerals. Due to the different causes of uneven expansion, the mechanical mechanism of cracking and the shape of the resulting cracks will be different. When the material is uniform and has no internal structural defects, the cracks gradually develop from the outside to the inside, showing a "wrapped" shape. In the case of microcracks inside, it will cause vertical chord-like tension cracks. The uneven distribution of clay minerals will result in different degrees of water swelling. When the content of clay minerals inside is greater than that of the outside, vertical tension cracks will be generated from the outside to the inside.

\section{Conclusion}

Through the swelling-cracking test of the expansive mudstone in the Central Sichuan red beds, the evolution characteristics of the swelling cracks were studied. The relationship between the water absorption and the crack degree during the evolution of the cracks was analyzed. Combined with a numerical analysis, the cracking mechanism of expansive rock is studied. The main conclusions are summarized as below:

(1) The swelling-cracking process has obvious threestage characteristics: the generation stage, the rapid 
development stage, and the stabilization stage. Among them, the increase in the crack degree during the rapid development stage accounts for $90 \%$ of the total process

(2) The final crack degree of swelling and cracking is related to the initial water content, water absorption method, and clay mineral content

(3) The development of swelling cracks of expansive rock is controlled by three characteristic values of water absorption. The first characteristic value $w_{1}$ is the water absorption at the beginning of cracks; the second characteristic value $w_{2}$ is the initial water absorption at the rapid development stage of cracks; the third characteristic value $w_{3}$ is the water absorption when crack development reaches a stable level. The second characteristic value $w_{2}$ is of great significance in engineering practice. It indicates that the development of cracks has entered a stage of rapid development, in which the crack degree increases exponentially with water absorption. This has a certain reference for the study of swelling rock slope instability under rainfall conditions

(4) Swelling and cracking of expansive rock is caused by uneven expansion, which is constantly changing over time. The main cause of uneven swelling is uneven water absorption and uneven distribution of swelling clay minerals. Due to the different causes of uneven expansion, the mechanical mechanism of cracking and the shape of the resulting cracks will be different

\section{Data Availability}

The data used to support the findings of this study are included within the article.

\section{Conflicts of Interest}

The authors declare no conflict of interest.

\section{Acknowledgments}

The authors are grateful for the financial support from the National Natural Science Foundation of China (Grant No. 41702337).

\section{References}

[1] C. G. Bao, B. W. Gong, and L. T. Zhan, "Properties of unsaturated soils and slope stability of expansive soils," in Proceedings of the Second International Conference on Unsaturated Soils, vol. 2, pp. 81-108, Wuhan, China, 1998.

[2] Y. Wang, C. H. Li, H. Liu, and J. Q. Han, "Fracture failure analysis of freeze-thawed granite containing natural fracture under uniaxial multi-level cyclic loads," Theoretical and Applied Fracture Mechanics, vol. 110, article 102782, 2020.

[3] Y. Wang, C. H. Li, and J. Q. Han, "On the effect of stress amplitude on fracture and energy evolution of pre- flawed granite under uniaxial increasing-amplitude fatigue loads," Engineering Fracture Mechanics, vol. 240, article 107366, 2020.

[4] Y. Wang, D. Q. Liu, J. Q. Han, C. H. Li, and H. Liu, "Effect of fatigue loading-confining stress unloading rate on marble mechanical behaviors: an insight into fracture evolution analyses," Journal of Rock Mechanics and Geotechnical Engineering, vol. 12, no. 6, pp. 1249-1262, 2020.

[5] B. W. Gong, C. W. Ng, and C. Bao, "Field study of the effects of rainfall infiltration on channel slope of expansive soil," Journal of Yangtze River Scientific Research Institute, vol. 19, no. S1, pp. 94-97, 2002.

[6] Y. Wang, Y. F. Yi, C. H. Li, and J. Q. Han, "Anisotropic fracture and energy characteristics of a Tibet marble exposed to multi-level constant-amplitude (MLCA) cyclic loads: a lab-scale testing," Engineering Fracture Mechanics, vol. 244, p. 107550, 2021.

[7] Z. Z. Yin, J. Wei, J. P. Yuan, and X. S. Cao, "Mechanism of slope slide of expansive soil and reinforcement for the slope," Journal of Hydraulic Engineering, vol. 41, no. 1, pp. 1-6, 2010.

[8] Z. Z. Yin, J. P. Yuan, J. Wei, X. S. Cao, H. Q. Liu, and B. Xu, "Influences of fissures on slope stability of expansive soil," Chinese Journal of Geotechnical Engineering, vol. 34, no. 12, pp. 2155-2161, 2012.

[9] Z. H. Chen, "On basic theories of unsaturated soils and special soils," Chinese Journal of Geotechnical Engineering, vol. 36, no. 2, pp. 201-272, 2014.

[10] Z. H. Lu, Z. H. Chen, and Y. B. Pu, "A CT study on the crake evolution of expansive soil during drying and wetting cycles," Rock and Soil Mechanics, vol. 23, no. 4, pp. 417-422, 2002.

[11] S. M. Yi, Z. H. Li, and Y. Z. Zhang, "The fractal characteristics of fractures in expansion soil and its significance," Chinese Journal of Geotechnical Engineering, vol. 3, pp. 294-298, 1999.

[12] J. Wang, B. W. Gong, J. J. Zhang, X. W. Zhou, and F. Y. Tan, "Field observation and description method of cracks development on expansive rock," Journal of Yangtze River Scientific Research Institute, vol. 27, no. 9, pp. 74-75, 2010.

[13] W. Li, G. S. Liu, and T. Yao, "Improvement of methods for crack image processing and crack feature extraction of expansive soil," Rock and Soil Mechanics, vol. 35, no. 12, pp. 36193626, 2014.

[14] B. X. Wei, B. Liu, and X. Liu, "Research on the quantitative basic index of expansive soil," Hydrogeology \& Engineering Geology, vol. 42, no. 5, pp. 84-89, 2015.

[15] C. S. Tang, Y. J. Cui, A. M. Tang, and B. Shi, "Shrinkage and desiccation cracking process of expansive soil and its temperature-dependent behaviour," Chinese Journal of Geotechnical Engineering, vol. 34, no. 12, pp. 2181-2187, 2012.

[16] X. Mao, S. J. Xin, M. S. Cheng, Z. H. Chen, and X. Q. Wang, "Mechanical behavior of expansive soil under initial damage and wetting-drying cycles," Rock and Soil Mechanics, vol. 39, no. 2, pp. 571-579, 2018.

[17] D. X. Hu, X. Li, C. Y. Zhou, L. Xue, and H. F. Liu, "Quantitative analysis of swelling and shrinkage cracks in expansive soil," Rock and Soil Mechanics, vol. 39, no. S1, pp. 318-324, 2018.

[18] Z. G. Lou, S. J. Wang, and Z. B. Yang, "Quantitative analysis of fracture evolution of expansive soils under wetting-drying cycles," Rock and Soil Mechanics, vol. 41, no. 7, pp. 23132323, 2020.

[19] Z. G. Lou, S. J. Wang, J. W. Zhang, and Z. B. Yang, “Thickness effect on crack evolution of expansive soil," Chinese Journal of Geotechnical Engineering, vol. 42, no. 10, pp. 1922-1930, 2020. 
[20] J. M. Konrad and R. Ayad, "Desiccation of a sensitive clay: field experimental observations," Canadian Geotechnical Journal, vol. 34, no. 6, pp. 929-942, 1997.

[21] H. L. Yao, S. H. Zheng, X. R. Ge, and S. X. Yi, "Assessment on slope stability in cracking expansive soils," Chinese Journal of Rock Mechanics and Engineering, vol. 21, no. A02, pp. 23312335, 2002.

[22] J. Ma, S. X. Chen, F. Yu, and M. G. Feng, "Experimental research on crack evolution process in fissured clay," Rock and Soil Mechanics, vol. 1, no. 10, pp. 2203-2208, 2007.

[23] J. H. Wu, J. P. Yuan, and C. W. Ng, "Theoretical and experimental study of initial cracking mechanism of an expansive soil due to moisture-change," Journal of Central South University, vol. 19, no. 5, pp. 1437-1446, 2012.

[24] D. X. Wu, H. J. Liu, and G. Q. Wang, "Laboratory experimental study of slaking characteristics of red-bed soft rock," Chinese Journal of Rock Mechanics and Engineering, vol. 9, no. S2, pp. 4173-4179, 2010.

[25] Y. Pan, Z. Liu, and C. Y. Zhou, "Experimental study of disintegration characteristics of red-bed soft rock within water and its interface model," Rock and Soil Mechanics, vol. 38, no. 11, pp. 3231-3239, 2017.

[26] S. K. Shan, X. L. Leng, and Q. Sheng, "Study on water swelling and softening characteristics of expansive rock," Rock and Soil Mechanics, vol. 41, no. 2, pp. 561-570, 2020.

[27] Z. B. Zhong, A. H. Li, R. G. Rong, P. P. Wu, and J. Xu, "Experimental study on the time-dependent swelling characteristics of red-bed mudstone in Central Sichuan," Chinese Journal of Rock Mechanics and Engineering, vol. 38, no. 1, pp. 76-86, 2019.

[28] F. Yu, X. X. Cui, S. X. Chen, Z. Zhou, and Z. J. Dai, "Experimental study on disintegration characteristics of swelling rock in Central Sichuan under dry-wet cycle," Journal of Henan Polytechnic University (Natural Science), vol. 38, no. 4, pp. 130-135, 2019.

[29] Z. J. Dai, J. H. Guo, Z. Zhou, S. X. Chen, J. Li, and F. Yu, "Inversion and prediction of long-term uplift deformation of highspeed railway subgrade in Central Sichuan red-bed," Chinese Journal of Rock Mechanics and Engineering, vol. 39, no. S2, pp. 3538-3548, 2020. 